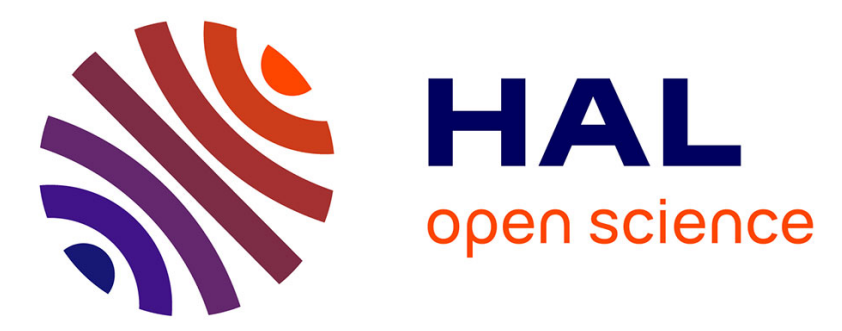

\title{
The Rhône-Aggregation Land Surface Scheme Intercomparison Project: An Overview
}

Aaron Anthony Boone, F. Habets, J. Noilhan, D. Clark, P. Dirmeyer, S. Fox, Y. Gusev, I. Haddeland, R. Koster, D. Lohmann, et al.

\section{To cite this version:}

Aaron Anthony Boone, F. Habets, J. Noilhan, D. Clark, P. Dirmeyer, et al.. The Rhône-Aggregation Land Surface Scheme Intercomparison Project: An Overview. Journal of Climate, 2004, 17 (1), pp.187-208. 10.1175/1520-0442(2004)0172.0.CO;2 . hal-02267753

\section{HAL Id: hal-02267753 https://hal.science/hal-02267753}

Submitted on 19 Aug 2019

HAL is a multi-disciplinary open access archive for the deposit and dissemination of scientific research documents, whether they are published or not. The documents may come from teaching and research institutions in France or abroad, or from public or private research centers.
L'archive ouverte pluridisciplinaire HAL, est destinée au dépôt et à la diffusion de documents scientifiques de niveau recherche, publiés ou non, émanant des établissements d'enseignement et de recherche français ou étrangers, des laboratoires publics ou privés. 


\title{
The Rhône-Aggregation Land Surface Scheme Intercomparison Project: An Overview
}

\author{
A. Boone, ${ }^{\mathrm{a}, \mathrm{q}}$ F. Habets, ${ }^{\mathrm{a}}$ J. Noilhan, ${ }^{\mathrm{a}}$ D. Clark, ${ }^{\mathrm{b}}$ P. Dirmeyer, ${ }^{\mathrm{c}}$ S. FoX, ${ }^{\mathrm{j}}$ Y. Gusev, ${ }^{\mathrm{d}}$ I. Haddeland,,${ }^{\mathrm{e}}$ \\ R. Koster,,${ }^{\mathrm{g}}$ D. Lohmann, ${ }^{\mathrm{h}}$ S. Mahanama, ${ }^{\mathrm{r}}$ K. Mitchell,${ }^{\mathrm{h}}{ }^{\mathrm{O}}$. Nasonova, ${ }^{\mathrm{d}}$ G.-Y. Niu, ${ }^{\mathrm{i}}$ A. Pitman, ${ }^{\mathrm{j}}$ \\ J. Polcher, ${ }^{k}$ A. B. Shmakin, ${ }^{1}$ K. Tanaka, ${ }^{\mathrm{m}}$ B. van den Hurk, ${ }^{\mathrm{n}}$ S. Vérant, ${ }^{\mathrm{k}}$ D. Verseghy, ${ }^{\circ}$ P. Viterbo, ${ }^{\mathrm{p}}$ \\ AND Z.-L. YANG ${ }^{\mathrm{s}}$ \\ ${ }^{a}$ Centre National de Recherche Météorologique/Météo-France, Toulouse, France \\ ${ }^{b}$ Centre for Ecology and Hydrology, Wallingford, United Kingdom \\ ${ }^{c}$ Center for Ocean-Land-Atmosphere Studies, Calverton, Maryland \\ 'Institute of Water Problems, Moscow, Russia \\ ${ }^{e}$ Department of Civil and Environmental Engineering, University of Washington, Seattle, Washington \\ ${ }^{f}$ Norwegian Water Resources and Energy Directorate (NVE), Oslo, Norway \\ ${ }^{8}$ NASA Goddard Space Flight Center, Greenbelt, Maryland \\ ${ }^{h}$ NOAA/NCEP/Environmental Modeling Center, Camp Springs, Maryland \\ iDepartment of Hydrology and Water Resources, The University of Arizona, Tucson, Arizona \\ iMacquarie University, North Ryde, Australia \\ ${ }^{k}$ Laboratoire de Météorologie Dynamique, Paris, France \\ Institute of Geography, Russian Academy of Sciences, Moscow, Russia \\ ${ }^{m}$ Water Resources Research Center, DPRI, Kyoto University, Gokasho, Japan \\ ${ }^{n}$ Royal Netherlands Meteorological Institute, De Bilt, Netherlands \\ ${ }^{\circ}$ Climate Research Branch, Meteorological Service of Canada, Toronto, Ontario, Canada \\ ${ }^{p}$ European Centre for Medium-Range Weather Forecasts, Reading, United Kingdom \\ ${ }^{q}$ Centres d'Etudes Spatiales de la Biosphère, Toulouse, France \\ ${ }^{r}$ Goddard Earth Sciences and Technology Center, NASA Goddard Space Flight Center, Greenbelt, Maryland \\ ${ }^{s}$ Department of Geological Sciences, University of Texas at Austin, Austin, Texas
}

(Manuscript received 16 August 2002, in final form 28 March 2003)

\section{ABSTRACT}

The Rhône-Aggregation (Rhône-AGG) Land Surface Scheme (LSS) intercomparison project is an initiative within the Global Energy and Water Cycle Experiment (GEWEX)/Global Land-Atmosphere System Study (GLASS) panel of the World Climate Research Programme (WCRP). It is a intermediate step leading up to the next phase of the Global Soil Wetness Project (GSWP) (Phase 2), for which there will be a broader investigation of the aggregation between global scales (GSWP-1) and the river scale. This project makes use of the Rhône modeling system, which was developed in recent years by the French research community in order to study the continental water cycle on a regional scale.

The main goals of this study are to investigate how 15 LSSs simulate the water balance for several annual cycles compared to data from a dense observation network consisting of daily discharge from over 145 gauges and daily snow depth from 24 sites, and to examine the impact of changing the spatial scale on the simulations. The overall evapotranspiration, runoff, and monthly change in water storage are similarly simulated by the LSSs, however, the differing partitioning among the fluxes results in very different river discharges and soil moisture equilibrium states. Subgrid runoff is especially important for discharge at the daily timescale and for smallerscale basins. Also, models using an explicit treatment of the snowpack compared better with the observations than simpler composite schemes.

Results from a series of scaling experiments are examined for which the spatial resolution of the computational grid is decreased to be consistent with large-scale atmospheric models. The impact of upscaling on the domainaveraged hydrological components is similar among most LSSs, with increased evaporation of water intercepted by the canopy and a decrease in surface runoff representing the most consistent inter-LSS responses. A significant finding is that the snow water equivalent is greatly reduced by upscaling in all LSSs but one that explicitly accounts for subgrid-scale orography effects on the atmospheric forcing.

Corresponding author address: Aaron A. Boone, Centres d'Etudes Spatiales de la Biosphère, 18, avenue Edouard Belin, Room 214, 31401 Toulouse, France. E-mail: aaron.boone@free.fr 


\section{Introduction}

The regional water cycle has become an increasingly studied phenomena in recent years owing to a variety of factors, such as dwindling freshwater resources relative to the ever-growing human population, the predicted adverse impacts of a theorized global warming, changes in water use because of anthropogenic effects (such as dams and irrigation), and changes in precipitation patterns due to natural climatic variability. One method used by the scientific community to improve the understanding of this complex system is the utilization of atmospheric and hydrological models. Significant improvements have been achieved in recent years, but there is still a lack of understanding of some of the basic mechanisms at work and how to accurately model them.

Atmospheric modelers attempt to improve the simulation of the hydrological cycle through the physical parameterizations related to precipitation. Hydrological modelers generally use relatively simple empirically based production functions as upper boundary conditions, while giving more detailed attention to subterranean water movement and river routing. The link between these models is the land surface scheme (LSS), which has the main functions of partitioning incoming atmospheric energy into fluxes of radiation, heat, mass, and momentum, and dividing the incoming precipitation into storage, runoff, and evaporative components. The LSS is therefore a key component of the simulation of the hydrological cycle.

\section{a. Subgrid processes and scaling}

One of the greatest challenges for a LSS is to be able to simulate quantities representative of average values over oftentimes heterogeneous surfaces. It is known that surface turbulent and radiative fluxes and near-surface hydrology can vary nonlinearly over the spatial scales typical of an atmospheric model grid element [e.g., 1033$10^{6} \mathrm{~km}^{2}$ for a typical global climate model (GCM)] or basin. This primarily arises due to subgrid spatial variability of soil and vegetation characteristics, topography, and near-surface water storage (canopy water interception, soil moisture, and snow cover). The parameterization of subgrid variability of surface characteristics and forcing in LSSs have a significant impact on regionally simulated near-surface hydrology using prescribed atmospheric forcing (Ghan et al. 1997) and it can have important feedbacks with the modeled atmosphere on regional scales (e.g., Wang and Eltahir 2000; Nykanen et al. 2001).

The simplest method to represent the surface is to use the single grid-box dominant surface type to determine the full set of parameters from a predetermined classification scheme or lookup table. The drawback of this method is that when two or more distinct surface types are present at a similar spatial coverage within the same box, simulated fluxes and near-surface hydrology can have significant errors due to the aforementioned nonlinearity of the associated processes. Parameter aggregation methods can be used to determine the average values based on the fractional area coverage or frequency of occurrence of varying surface types within a grid box. Such methods provide more representative grid-box average parameters provided that the aggregated values still have a physical meaning (HendersonSellers and Pitman 1992), and that aggregation operators are consistent with the averaging process of the surface fluxes (Noilhan and Lacarrère 1995).

In recent years, an increasing number of LSSs have adopted the so-called tile approach for which the gridbox surface is divided into a series of subgrid patches (e.g., Avissar and Pielke 1989; Koster and Suarez 1992; Seth et al. 1994). This method has the advantage of explicitly representing very distinct surface types, and that specific properties (such as elevation, soil type, and land cover) can be assigned to each tile. The main disadvantage is that a potentially large number of variables and parameters must be stored in memory and computational expense can be greatly increased compared to the effective surface treatment. This is an especially important consideration for numerical weather prediction (NWP) or GCM applications.

There are also methods which account for subgrid effects on certain processes. There are numerous methods that parameterize subgrid hydrology as a function of the variability in soil properties (Dümenil and Todini 1992; Liang et al. 1994; Liang and Xie 2001). Probability distribution functions can be applied to certain key LSS variables (such as soil moisture) using statistical moments calculated from observations (Wetzel and Chang 1988; Entekhabi and Eagleson 1989). The subgrid parameterization of atmospheric forcing variables, such as precipitation coverage, can also be modeled (Dolman and Gregory 1992; Liang et al. 1996). The widespread implementation of such methods into LSSs are hindered, to some extent, by limited observational data spanning large spatial scales and time records. In contrast, schemes using subgrid topographic variability (Flamiglietti and Wood 1994) have become popular in recent years because topographic data is available at increasingly higher spatial resolutions.

\section{b. LSS intercomparison studies}

Numerous field experiments have been done over the years with the objective of improving the understanding of the link between the land surface and the atmosphere. Some examples of some of the most published studies are Hydrological-Atmospheric pilot Experiment-Modelisation du Bilan Hydrique (HAPEX-MOBILHY; André et al. 1986), First International Satellite Land Surface Climatology Project (ISLCP) Field Experiment (FIFE; Sellers et al. 1988), Boreal Ecosystem-Atmo- 
sphere Study (BOREAS; Sellers et al. 1997), and Cabauw. Netherlands (Beljaars and Bosveld 1997). These datasets have proven to be of value in terms of LSS model development, evaluation, and intercomparison studies. In particular, the Project for the Intercomparison of Land Surface Parameterization Schemes (PILPS; Henderson-Sellers et al. 1993) has increased the understanding of LSS models, and it has lead to many improvements in the schemes themselves. In phase 2 of PILPS (Henderson-Sellers et al. 1995), LSSs have been used in so-called "offline mode" (driven using prescribed atmospheric forcing), and the resulting simulations have been compared to observed data.

The first attempt by PILPS to address LSS behavior at a regional scale was undertaken in PILPS-2c (Wood et al. 1998). Multiyear basin-scale LSS simulations over the southern central plains of the United States were evaluated using a river routing model and observed daily river discharge. Subgrid runoff parameterizations were shown to be of critical importance in terms of correctly simulating river discharge for the spatial scales considered $\left(1^{\circ} \times 1^{\circ}\right.$ grid elements). PILPS-2e (Bowling et al. 2002) is similar to Phase-2c, except that the basin is located at a relatively high latitude with a considerable coverage of lakes and wetlands (at a $1 / 4^{\circ} \times 1 / 4^{\circ}$ spatial resolution). River flows are controlled to a large extent by lake and soil freeze-thaw and snow melt.

The Global Soil Wetness Project (GSWP; Phase 1; Dirmeyer et al. 1999) was an offline LSS intercomparison study which produced 2-yr global datasets of soil moisture, surface fluxes, and related hydrological quantities. This project was used as a means for testing and developing large-scale validation techniques over land; it served as a large-scale validation and quality check of the ISLSCP Initiative I (Meeson et al. 1995; Sellers et al. 1995) datasets; it undertook a global comparison of a number of LSSs, and it included a series of sensitivity studies of specific parameterizations (which lead to improvements in some models). This paper describes the Rhône-Aggregation LSS intercomparison project (Rhône-AGG), which is an intermediate step leading up to the next phase of the GSWP (Phase 2), for which there will be a broader investigation of the aggregation between global scales (GSWP-1) and the river scale. This project differs from the aforementioned PILPS basin-scale studies primarily because the very high spatial resolution observational data within the Rhône basin makes it possible to examine the impact of scaling on LSS simulations.

The remainder of this paper is divided into five sections. The Rhône modeling system is described in section 2, the Rhône-AGG project overview is given in section 3 , the experimental design is presented in section 4 , section 5 consists of a general overview of the results, and the conclusions are presented in the last section. This paper gives relevant details on the evaluation of the LSSs using observations and the impact of simple upscaling of the computational grid. A more detailed

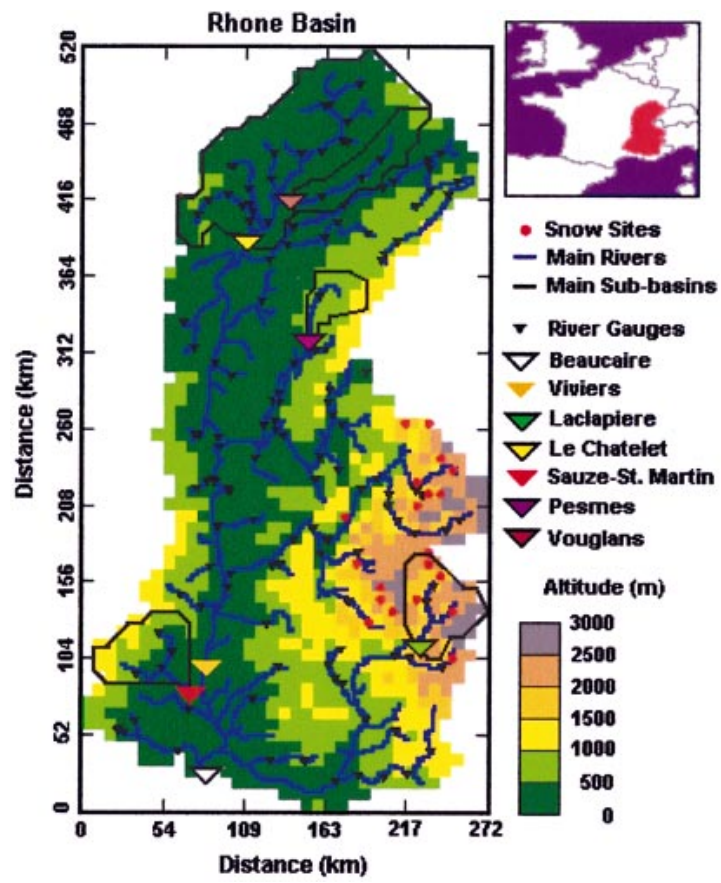

FIG. 1. The Rhône model domain with gridded topography at 500$\mathrm{m}$ intervals. The 145 gauging station locations (filled triangles) and the snow observation sites (filled red circles). The major rivers are shown in blue. The three subbasins given special treatment in RhôneAGG are outlined, along with two used for model calibration. (upper right) The basin location relative to France.

analysis of the experimental results including a more comprehensive investigation of parameter aggregation methods and a comparison with observations will be reviewed in two forthcoming companion papers. The purpose of this paper is to give a general overview of the project and of the results, while leaving further detail to the two aforementioned papers.

\section{GEWEX-Rhône modeling system}

The Rhône is the largest European river flowing into the Mediterranean Sea. The corresponding basin covers over $86000 \mathrm{~km}^{2}$ of southeastern France (Fig. 1). Surface characteristics, subsurface parameters, and atmospheric forcing are mapped onto this domain under the fellowship of the GEWEX-Rhône project which was conceived in recent years by the French research community in order to study the continental water cycle on a regional scale. Three distinct components comprise the corresponding modeling system (Habets et al. 1999): an analysis system to determine the near-surface atmospheric forcing, a LSS interface, and a distributed hydrological model. The coupling between the components of the system is one-way (as shown in the schematic in Fig. 2), and the variables transferred between each component are indicated in the rectangles connected to arrows. 


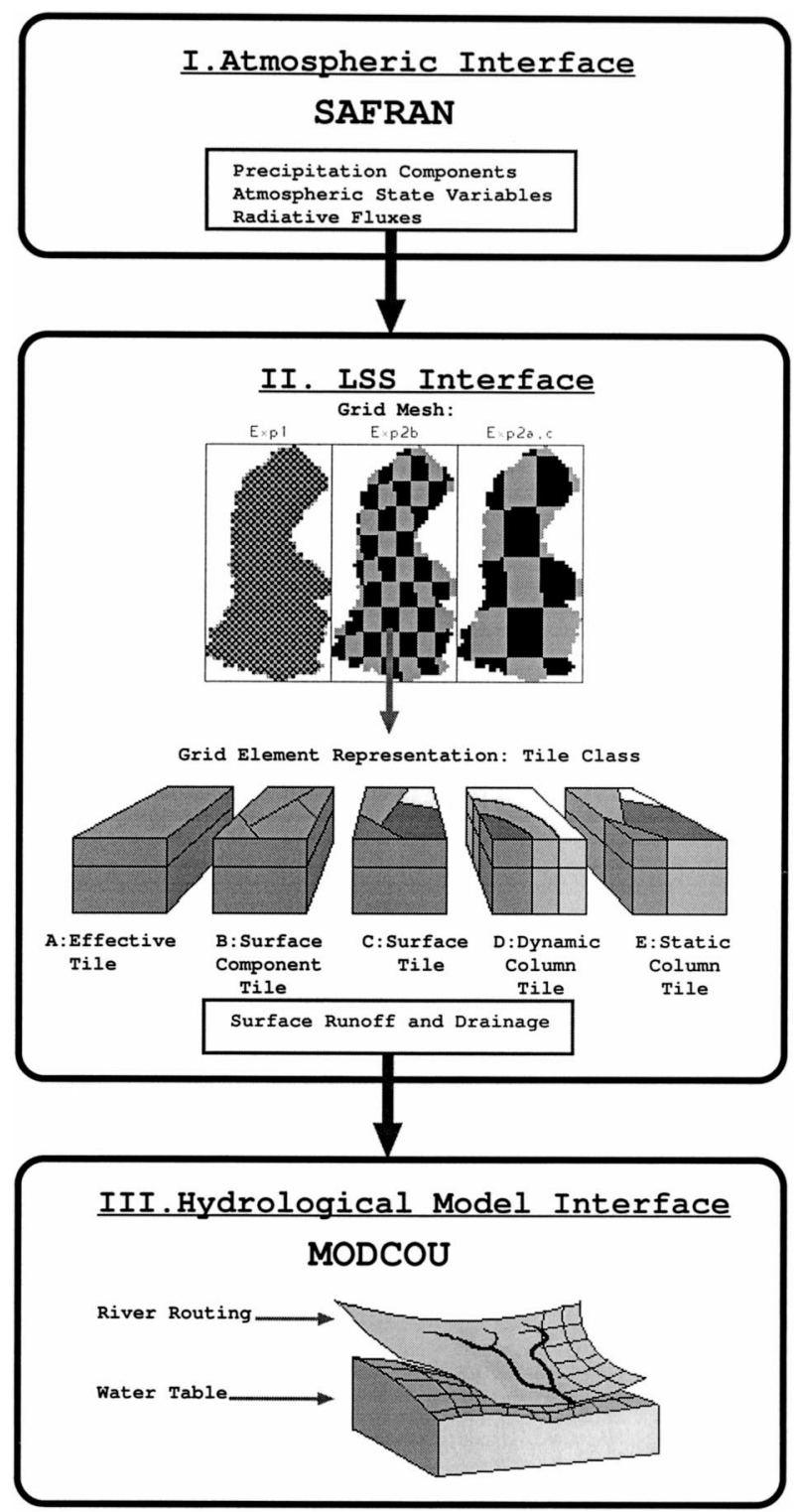

FIG. 2. The Rhône modeling system components. The participating LSSs are substituted into the LSS interface (II) The coupling is one way, and the variables that are transferred between each component are represented in blue. The LSS grids used for the scaling experiments (Exp1: $8 \mathrm{~km}$; Exp2b: $0.5^{\circ}$, Exp2a: $1^{\circ}$ ) and a basic representation of LSS tiling methods are also shown.

\section{a. Forcing and parameter data}

The domain is divided up into $14718 \mathrm{~km} \times 8 \mathrm{~km}$ grid boxes. The gridded topography is shown using 500$\mathrm{m}$ increments in Fig. 1. The atmospheric forcing is calculated using the Système d'Analyse Fournissant des Renseignements Atmosphériques à la Neige: Analysis System for Providing Atmospheric Information Relevant to Snow (SAFRAN) analysis system (Durand et al. 1993). The input atmospheric data consist of standard screen-level observations at approximately 60 MétéoFrance weather network sites within the domain. Eu-
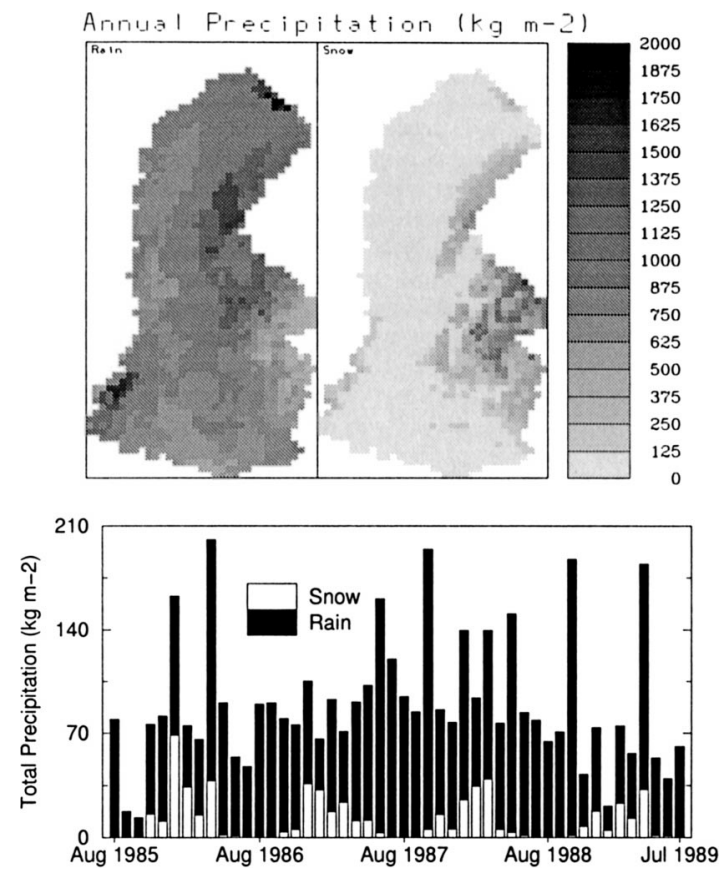

FIG. 3. (top) The prescribed total annual snow and rain components averaged over 4 yr (1985-89) over the Rhône basin. (bottom) The corresponding monthly basin totals.

ropean Centre for Medium-Range Weather Forecasts (ECMWF) analyses and climatological data for 249 homogeneous climatic zones, and total daily precipitation data from over 1500 gauges.

The provided forcing variables (at a 3-h time interval) are the air temperature at $2 \mathrm{~m}$, wind speed at $10 \mathrm{~m}$, specific humidity at $2 \mathrm{~m}$, downwelling visible solar radiation, downwelling longwave atmospheric radiation, liquid precipitation rate, liquid water equivalent snow/ solid precipitation rate, and surface pressure. Four years worth of forcing are used in the current study (198589) which coincide with the GSWP (1987-88) simulations. The 4-yr annual average solid and liquid precipitation components are shown in Fig. 3. Orographic lifting plays a crucial role in precipitation enhancement, while the lowest precipitation values occur near the south-central part of the basin. In addition, there is a significant snow component in mountainous areas (comprising approximately $10 \%$ of the total annual basinwide precipitation). See Etchevers et al. (2001) for further details on the forcing database.

The soil parameters are defined using the soil textural properties (described by King et al. 1995). The vegetation parameters are defined using a vegetation map from the Corine Land Cover Archive (Giordano 1992) and a 2-yr satellite archive of the Advanced Very High Resolution Radiometer/normalized difference vegetation index (AVHRR/NDVI; Champeaux et al. 2000). There are 10 distinct surface types considered for Rhône-AGG, and are listed with their corresponding index and surface properties in Table 1. 
TABLE 1. The surface classes and the corresponding vegetation parameters. The overbar denotes a linear average over 12 months, where $R_{\text {smin }}, d_{\text {root }}, \alpha$, LAI, veg, and $z_{0}$ represent the minimum stomatal resistance, the rooting depth, the snow-free all-wavelength albedo, the leaf area index, the area vegetation cover fraction, and the snow-free surface roughness length, respectively.

\begin{tabular}{|c|c|c|c|c|c|c|c|}
\hline Class & Description & $R_{s \min }\left(\mathrm{s}^{-1} \mathrm{~m}\right)$ & $d_{\text {root }}(\mathrm{m})$ & $\alpha(-)$ & $\overline{\mathrm{LAI}}\left(\mathrm{m}^{2} \mathrm{~m}^{-2}\right)$ & $\overline{\operatorname{veg}}(-)$ & $\overline{z_{0}}(\mathrm{~m})$ \\
\hline 1 & Crops A & 40 & 1.5 & 0.20 & 2.33 & 0.71 & 0.05 \\
\hline 2 & Mediterranean crops & 40 & 1.5 & 0.20 & 0.58 & 0.29 & 0.02 \\
\hline 3 & Cereals A & 40 & 1.5 & 0.20 & 1.79 & 0.55 & 0.04 \\
\hline 4 & Crops B & 40 & 1.5 & 0.20 & 1.67 & 0.60 & 0.04 \\
\hline 5 & Cereals B & 40 & 1.5 & 0.20 & 1.67 & 0.54 & 0.04 \\
\hline 6 & Crops and grassland & 40 & 1.0 & 0.17 & 1.92 & 0.65 & 0.05 \\
\hline 7 & Grassland & 40 & 1.0 & 0.17 & 2.00 & 0.65 & 0.06 \\
\hline 8 & Coniferous forest & 150 & 2.0 & 0.15 & 2.75 & 0.73 & 1.00 \\
\hline 9 & Rocks & & & 0.19 & 0.00 & 0.00 & 0.01 \\
\hline 10 & Deciduous forest & 150 & 2.0 & 0.15 & 1.63 & 0.48 & 1.00 \\
\hline
\end{tabular}

\section{b. Hydrological model}

The Rhône modeling system incorporates the distributed hydrological model Modél Couplé de l'Ecoé des Mines de Paris (MODCOU; Ledoux et al. 1989; Violette et al. 1997). It uses a two-layer approach: the underground (lower of the two) layer encompasses the aquifers for the Rhône and Saône valleys and is active below approximately $21 \%$ of the total surface area of the basin, while the surface layer corresponds to the atmospheric forcing domain and contains 27054 grid elements (between 1 and 64 such cells are within each atmospheric grid box). Topographical data are used to determine the surface hydrographic network and the water transfer time constant between each hydrological grid cell. The water table transmissivity and storage coefficients have been calibrated using the observed streamflow (GolazCavazzi et al. 2001).

\section{c. LSS interface}

The function of the LSS interface between SAFRAN and MODCOU is to model the rapid interaction between the atmosphere and the surface through an explicit resolution of the daily cycle, and also the slower interaction with the deep soil layers and the hydrological system. LSS output surface runoff is transferred to the surface layer, and routing from each grid cell is based on isochronous zones using a time step of 1 day. LSS output drainage acts as a source for the water table, which is modeled using the diffusivity equation. There is currently no feedback between the water table and the LSS. The water table can be either a source or a sink for rivers based on the local water table depth relative to the channel water height.

It is important to note that the other two components of the system (i.e., SAFRAN and MODCOU) have been developed and calibrated independently of any particular LSS, so that different LSSs can easily be inserted into the system. The LSSs that are incorporated into this system for the Rhône-AGG project are listed in Table 2. Further details related to the model coupling can be found in Habets et al. (1999).

\section{d. Observations for LSS evaluation}

Two sets of observations are used for evaluating model simulations for the Rhône basin. The first consists of 24 daily snow depth observation sites located within the French Alps (circles in Fig. 1). These sites are selected from a much larger station database using criteria based on quality control, and by only considering stations with an elevation difference between the site and the gridbox mean altitude of $250 \mathrm{~m}$ or less.

The second set of observations consist of daily streamflow data at 145 river gauges, which are used for validation of the simulated discharge (filled triangles in Fig. 1). Based on the work of Etchevers et al. (2001) and Habets et al. (1999), only basins with surface areas of at least $250 \mathrm{~km}^{2}$ are used in the modeling system. Damming impacts the flow in some mountainous basins; however, there are a significant number of mountainous basins for which anthropogenic effects are minor or nonexistent. Quantitative information on dams is not available (this information is withheld by the French water management agencies), but estimates of such effects are made for some of the larger basins using the observed discharge and the measured precipitation.

\section{The Rhône-AGG project}

The Rhône-AGG is an initiative within the Global Energy and Water Cycle Experiment (GEWEX) Global Land-Atmosphere System Study (GLASS; Polcher et al. 2000). This study makes use of the infrastructure and developments resulting from the GEWEX-Rhône project. The ultimate goals of this project are similar to that of PILPS, which are to increase the understanding of LSSs, and to provide explanations on the differences between simulations. It most resembles phases $2 \mathrm{c}$ and $2 \mathrm{e}$, in that observed river discharge at a basin scale (and snow depth observations at the local scale in phase-2e) are used to evaluate the LSSs. This project differs from the aforementioned PILPS projects owing to the much higher spatial resolution of the gridded atmospheric forcing and surface parameters, the large within-basin range in vegetation types (see Table 1) and climate 
TABLE 2. The Rhône-AGG participant LSSs. A single, relatively recent reference is shown for each LSS. The LSS symbol identifiers used throughout this paper are shown in the second column from the left (ID).

\begin{tabular}{|c|c|c|c|}
\hline LSS & ID & Name & Reference \\
\hline ISBA & A & $\begin{array}{l}\text { Interactions between Soil-Biosphere-Atmo- } \\
\text { sphere }\end{array}$ & Noilhan and Mahfouf (1996) \\
\hline NOAH & $\mathrm{B}$ & $\begin{array}{l}\text { NCEP/Oregon State University/Air Force/ } \\
\text { NWS Hydrologic Research Laboratory }\end{array}$ & Chen et al. (1997) \\
\hline COLA & $\mathrm{C}$ & $\begin{array}{l}\text { COLA/SSiB (Center for Ocean-Land-Atmo- } \\
\text { sphere Studies/Simple Biosphere Model) }\end{array}$ & Xue et al. (1991) \\
\hline MOSES-PDM & $\mathrm{D}$ & $\begin{array}{l}\text { Met Office Surface Exchange Scheme-Prob- } \\
\text { ability-Distributed Moisture }\end{array}$ & Blyth (2002) \\
\hline ECMWF & $\mathrm{E}$ & $\begin{array}{l}\text { European Centre for Medium-Range Weath- } \\
\text { er Forecasts scheme }\end{array}$ & Van den Hurk et al. (2000) \\
\hline NSIPP & $\mathrm{F}$ & $\begin{array}{l}\text { NASA Seasonal-to-Interannual Prediction } \\
\text { Project Catchment Model }\end{array}$ & Koster et al. (2000) \\
\hline VIC & $\mathrm{G}$ & Varible Infiltration Capacity Model & Liang et al. (1994) \\
\hline MECMWF & $\mathrm{H}$ & Modified ECMWF scheme & Van den Hurk and Viterbo (2002) \\
\hline SWAP & $\mathrm{S}$ & Soil-Water-Atmosphere-Plants & Gusev and Nasonova (1998) \\
\hline VISA & $\mathrm{J}$ & $\begin{array}{l}\text { Versatile Integrator of Surface-Atmospheric } \\
\text { Processes }\end{array}$ & Yang and Niu (2002) \\
\hline SPONSOR & $\mathrm{K}$ & $\begin{array}{l}\text { Semidistributed Parameterization Scheme of } \\
\text { Orography-Induced Hydrology }\end{array}$ & Shmakin (1998) \\
\hline CLASS & $\mathrm{L}$ & Canadian Land Surface Scheme & Verseghy (2000) \\
\hline ORCHIDEE & M & $\begin{array}{l}\text { Laboratoire de Météorologie Dynamique } \\
\text { (LMD) surface model }\end{array}$ & de Rosnay and Polcher (1998) \\
\hline SIBUC & $\mathrm{N}$ & $\begin{array}{l}\text { Simple Biosphere Model Including Urban } \\
\text { Canopy }\end{array}$ & Tanaka et al. (1998) \\
\hline CHASM & $\mathrm{O}$ & Chameleon Surface Model & Desborough (1999) \\
\hline
\end{tabular}

(Mediterranean, maritime-continental, and alpine), the large grid-box average altitude gradient $(3000 \mathrm{~m}$ over a horizontal distance of approximately $300 \mathrm{~km}$ ), and the comparatively large quantity of observational data for evaluating the schemes.

The objective of exploring LSS-scaling issues addresses one of the key questions to come out of the La Jolla International Geosphere-Biosphere Programme (IGBP)/GEWEX workshop (Dolman and Dickinson 1997): How are the simulations from a wide range of LSSs-currently used in GCMs, atmospheric models, or for local-scale studies-impacted by changing the spatial resolution? The Rhône-AGG project attempts to address this issue, and the main scientific questions of this project are:

1) How do the various LSSs simulate the discharge compared to the observed values for the entire basin and for various subbasins for several annual cycles?

2) Are the subgrid parameterizations for surface runoff and drainage scale-dependent?

3) How do the varying aggregation or tiling methods impact the results?

4) How does soil moisture scale in the LSSs?

5) What is the impact of grid resolution on the simulated snow water equivalent (SWE) and the associated snowmelt runoff?

\section{Experimental design}

The first year (ending 31 July 1986) is treated as a spinup year, so that only the results for the final $3 \mathrm{yr}$ are analyzed in this study. The daily discharge for two subbasins for the four simulation years is provided to the participants for an optional calibration of hydrological-model parameters (see section 4c, for more details). The provided land surface parameters are put into two basic groups based on whether or not they can be altered or replaced by the participants (see Table 3). Models were generally able to conform to most or all of the Rhône-AGG specifications. Two optional sets of hydraulic parameters are provided (Cosby et al. 1984; Noilhan and Lacarrère 1995), however the parameter values are similar except for the most coarse soils. The forcing variable definitions, sign conventions, and units follow the Assistance for Land-surface Modelling Activities (ALMA; Polcher 2001) data convention, which has been set up as a part of GLASS, and they are used throughout this paper.

\section{a. LSS Classification}

A summary of the LSS subgrid parameterization methods used for Rhône-AGG is listed in Table 4. The tiling methods are shown schematically in Fig. 2. Six of the fifteen participant LSSs use the single-tile approach at each grid point (tile class A in Fig. 2). The remaining LSSs use the multiple-tile method. Such tiling can be at the surface (class C, Fig. 2) or it may extend vertically throughout the soil-vegetation-snow column (class E, Fig. 2). Class B represents a simpler case for which only one component of the energy balance is tiled. Class D is similar to E, except that the 
TABLE 3. Land surface parameter values averaged over the entire $8 \mathrm{~km} \times 8 \mathrm{~km}$ resolution domain. An asterisk denotes parameters for which the corresponding values were not to be altered or replaced by the LSS modelers. Hydrological parameter values from Noilhan and Lacarrére (1995) are shown. The average in space (and time) is shown (denoted as Avg). Spatial averages are linear except for the hydraulic conductivity and matric potential at saturation (logarithmic), the minimum stomatal resistance (inverse), and the surface roughness length (natural-log).

\begin{tabular}{|c|c|c|c|c|}
\hline Variable description & Symbol & Avg & Range & Units \\
\hline *Clay fraction & $X_{\text {clay }}$ & 0.22 & $(0.47,0.04)$ & - \\
\hline *Sand fraction & $X_{\text {sand }}$ & 0.31 & $(0.89,0.07)$ & - \\
\hline *Total soil depth & $d_{\text {tot }}$ & 2.25 & $(3.00,1.00)$ & $\mathrm{m}$ \\
\hline Rooting depth & $d_{\text {root }}$ & 1.54 & $(2.00,1.00)$ & $\mathrm{m}$ \\
\hline Field capacity volumetric water content & $w_{\mathrm{fc}}$ & 0.26 & $(0.34,0.15)$ & $\mathrm{m}^{3} \mathrm{~m}^{-3}$ \\
\hline Wilting point volumetric water content & $w_{\text {wilt }}$ & 0.17 & $(0.26,0.07)$ & $\mathrm{m}^{3} \mathrm{~m}^{-3}$ \\
\hline Soil porosity & $w_{\text {sat }}$ & 0.47 & $(0.49,0.40)$ & $\mathrm{m}^{3} \mathrm{~m}^{-3}$ \\
\hline Hydraulic conductivity & $k_{\text {sat }}$ & 5.51 & $(181,1.31)$ & $\times 10^{-6} \mathrm{~m} \mathrm{~s}^{-1}$ \\
\hline Matric potential at saturation & $\psi_{\text {sat }}$ & -0.38 & $(-0.61,-0.11)$ & $\mathrm{m}$ \\
\hline$b$-parameter & $b$ & 6.43 & $(9.94,4.05)$ & - \\
\hline *Snow-free surface albedo & $\alpha$ & 0.17 & $(0.20,0.15)$ & - \\
\hline Minimum stomatal resistance & $R_{s \min }$ & 63.12 & $(150,40)$ & $\mathrm{s} \mathrm{m}^{-1}$ \\
\hline *Leaf area index (monthly) & LAI & 1.93 & $(4.00,0.00)$ & $\mathrm{m}^{2} \mathrm{~m}^{-2}$ \\
\hline *Snow-free surface roughness (monthly) & $z_{0}$ & 0.15 & $(1.00,0.01)$ & $\mathrm{m}$ \\
\hline Vegetation cover fraction (monthly) & veg & 0.58 & $(0.91,0.00)$ & - \\
\hline
\end{tabular}

fractions vary dynamically following a LSS state variable (such as a saturated zone).

The snow scheme classification is a simplified version of that proposed by Slater et al. (2001). For the current study, composite schemes are classified as those that calculate the snow thermal state and melt using a single energy budget for a mixed snow soil/vegetation layer or a shared soil grid. Explicit schemes use a distinct bulk or multiple-layer configuration and an independent energy budget with thermal properties depending on snow alone.

The method for representing subgrid surface runoff is shown in the rightmost column. Here, VIC represents the Variable Infiltration Method (Wood et al. 1992), TOPM represents the Topography-Based Hydrological Model (Beven and Kirby 1979) approach. Arno-top rep- resents the topographically controlled runoff scheme described by Dümenil and Todini (1992), and Carea represents a topographically controlled contributing area approach (Shmakin 1998). Three LSSs use probability density functions (pdfs) to describe the distribution of soil moisture or soil hydraulic parameters in order to modify the soil infiltration rate. All of these schemes assume that some subgrid fraction of the surface is saturated, thereby generating saturated-overland flow.

\section{b. Experiments}

Three sets of experiments designed to examine the impact of scaling are reviewed in this study (two additional experiments will be described in more detail in a forthcoming paper).

TABLE 4. The LSS configuration for Rhône-AGG. Ntiles represents the maximum number of tiles per grid box. For schemes with a single tile, the parameter aggregation method (EFF = effective or DOM = dominant) is shown. The snow scheme classification $(\mathrm{E}=\mathrm{explicit}, \mathrm{C}$ $=$ composite) is preceded by the total number of layers, and $\mathrm{R}$ is used to indicate if ripening is simulated. The tile class or type (refer to Fig. 2) is shown with the maximum number of soil columns per grid box (if greater then 1). The number of soil layers is shown for water (w) and temperature $(T)$. The total soil depth is $d_{\text {soil }}$, where $\bar{d}_{\text {tot }}$ represents the basin-average soil depth applied at all grid points $(2.4$ m). The absence of an overbar represents spatially variable values. The indication of a subgrid runoff scheme is shown in the last column.

\begin{tabular}{|c|c|c|c|c|c|c|}
\hline LSS & Ntiles/grid & Snow scheme & Tile type & Nlayers $T, w$ & $d_{\text {soil }}(\mathrm{ms})$ & Subgrid runoff \\
\hline ISBA & 1-EFF & $3 \mathrm{E} \mathrm{R}$ & A & 2,3 & $d_{\text {tot }}$ & VIC \\
\hline NOAH & 1-DOM & $1 \mathrm{C}-$ & A & 4,4 & $d_{\text {tot }}$ & $\operatorname{pdf}(w)$ \\
\hline COLA & 1-EFF & $1 \mathrm{C}-$ & A & 3,3 & $d_{\text {tot }}$ & - \\
\hline MOSES & 10 & $1 \mathrm{C}-$ & $\mathrm{C}$ & 4,4 & $\bar{d}_{\text {tot }}$ & $\operatorname{pdf}\left(w_{1}\right)$ \\
\hline ECMWF & 6 & $1 \mathrm{E}-$ & $\mathrm{C}$ & 4,4 & 2.89 & - \\
\hline NSIPP & 3 & $3 E R$ & D-3 & 7,3 & $d_{\mathrm{tot}}$ & TOPM \\
\hline VIC & $10 \times 10$ & $2 \mathrm{E} \mathrm{R}$ & $\mathrm{C}$ & 3,3 & $d_{\text {tot }}$ & VIC \\
\hline MECMWF & 6 & $1 \mathrm{E}-$ & $\mathrm{C}$ & 4,4 & 2.89 & Arno-top \\
\hline SWAP & 1-EFF & $2 \mathrm{E} \mathrm{R}$ & A & 2,2 & $d_{\text {tot }}$ & $\operatorname{pdf}\left(k_{\text {sat }}\right)$ \\
\hline VISA & 5 & $3 \mathrm{E} R$ & $\mathrm{C}$ & 6,6 & $\bar{d}_{\text {tot }}$ & TOPM \\
\hline SPONSOR & 1-EFF & $1 \mathrm{E} R$ & A & 3,2 & $d_{\mathrm{tot}}$ & CArea \\
\hline CLASS & 1-EFF & $1 \mathrm{E} R$ & A & 3,3 & $d_{\text {tot }}$ & - \\
\hline ORCHIDEE & 13 & $1 \mathrm{C}-$ & B & 7,2 & 2.00 & - \\
\hline SIBUC & 10 & $2 \mathrm{C}-$ & E-10 & 2,3 & $d_{\text {tot }}$ & - \\
\hline CHASM & 2 & $1 \mathrm{C}-$ & $\mathrm{C}$ & 5,1 & $d_{\text {root }}$ & - \\
\hline
\end{tabular}


1) The first (control) experiment (Exp1) consists of running the LSS on a high-resolution grid (see Fig. 2). The normalized fraction of the 10 surface types (see Table 1) within each grid box is supplied to participants, and a 1-km digital elevation model is also available. This information is to be used to define the subgrid properties for the tile schemes. Nontile schemes use the effective [or dominant for one LSS: National Centers for Environmental Prediction/ Oregon State University/Airforce/National Weather Service Hydrologic Research Laboratory (NOAH)] parameters. The LSS-simulated runoff from this experiment is used to drive the hydrological model MODCOU, and the simulated discharge and snow depth are evaluated using the observed data.

2) In Exp2a, simulations are run at a $1^{\circ}$ resolution (approximately $69 \mathrm{~km}$ ) corresponding to a GCM grid box (see Fig. 2). The purpose of these simulations is to examine the impact of upscaling on the water and energy budget components. The grid mask is consistent with the grid configuration used by the GSWP (Fig. 2). The surface parameters are aggregated using the basic rules of Noilhan and Lacarrère (1995): The minimum stomatal resistance $\left(R_{\text {smin }}\right)$ is aggregated using an inverse average, the aggregated snow-free surface roughness length is calculated using an exponential average, while a simple linear operator is used for the soil texture components, the total soil depth, and the remaining vegetation parameters listed in Table 3 . The provided effective soil hydraulic parameters for the $1^{\circ} \times 1^{\circ}$ grid are calculated using the aggregated grid-box soil texture components. All of the LSSs use these parameters, except for Met Office Surface Exchange Scheme (MOSES), which uses the aggregated soil hydraulic parameters.

3) In Exp2b, the schemes are run as in Exp2a, but for 57 boxes defined by overlaying a $1 / 2^{\circ} \times 1 / 2^{\circ}$ grid. The purpose of this experiment is to examine an intermediate spatial scale, which might be more typical of an NWP or mesoscale model. Note that the models did not recalibrate their hydrological parameters for the lower spatial resolution experiments (as the provided discharge from the two calibration subbasins could not be used at the lower resolutions).

\section{c. Calibration}

Six of the fifteen LSSs used the provided discharge for two subbasins (shown in Fig. 1) to calibrate certain model parameters. The Ognon (outlet at Pesmes) and the Ain (outlet at Vouglans) have surface areas of 2040 and $1120 \mathrm{~km}^{2}$, respectively. MOSES tuned the surfacelayer soil moisture distribution parameter, which controls subgrid infiltration and runoff. NASA Seasonalto-Interannual Prediction Project (NSIPP) and Versatile Integrator of Surface-Atmospheric Processes (VISA) calibrated the exponential decay factor for the saturated hydraulic conductivity (which impacts the depth to the saturated zone and correspondingly both runoff components), and VISA also modified the root-zone density distribution factor. VIC calibrated three runoff parameters: the subgrid surface runoff slope parameter, and two baseflow parameters. In addition, the elevation band lapse-rate parameter is changed from the default value to a calibrated value for the VIC rerun (which improved the snowpack simulation). The Interactions Between Soil-Biosphere-Atmosphere LSS (ISBA) calibrated a baseflow parameter that maintains a minimum baseflow (which is only important in prolonged dry conditions or in mountainous zones). Semidistributed Parameterization Scheme of Orography-Induced Hydrology (SPONSOR) calibrated the soil thermal conductivity, which impacts the surface energy budget and soil heat transfer. The ISBA calibration parameter varies in space and the values are biggest in regions with large topographic variability. All of the remaining aforementioned schemes applied constant calibrated values throughout the basin.

\section{Simulation results}

The baseline simulations of 15 LSSs are analyzed in this study. A number of LSS submitted reruns (with various motivations) after preliminary results were presented at the Rhône-AGG workshop. The SPONSOR scheme improved snow physics (to better model alpine conditions) and adjusted parameters controlling runoff. The VIC scheme used an improved temperature lapserate parameter for calculating the partitioning between snow and rain and the atmospheric temperature for each subgrid elevation band/tile. Laboratoire de Météorologie Dynamique Surface Model (ORCHIDEE) used its default lookup table parameter values in their original run, but used values derived from the Rhône-AGG parameters in the rerun thereby improving its evapotranspiration simulation. The remaining two schemes compared effective and tile configurations: Canadian Land Surface Scheme (CLASS) ran a new multitile version (class C), while MOSES ran a single-tile version of the model (class A).

\section{a. Experiment 1: Control}

\section{1) Surface FluXes AND HYDROLOGY}

A general intercomparison of the 3-yr domain-average LSS-simulated near-surface hydrology and surface fluxes is shown in Fig. 4, and the symbol entries to the LSSs are shown in Table 2. Note that LSS reruns are denoted using the corresponding lowercase letters.

The total simulated runoff (surface: Qs and drainage/ baseflow: Qsb) versus evapotranspiration (including sublimation) is shown in Fig. 4a, along with the observed runoff measured daily at Beaucaire (see Fig. 1). 

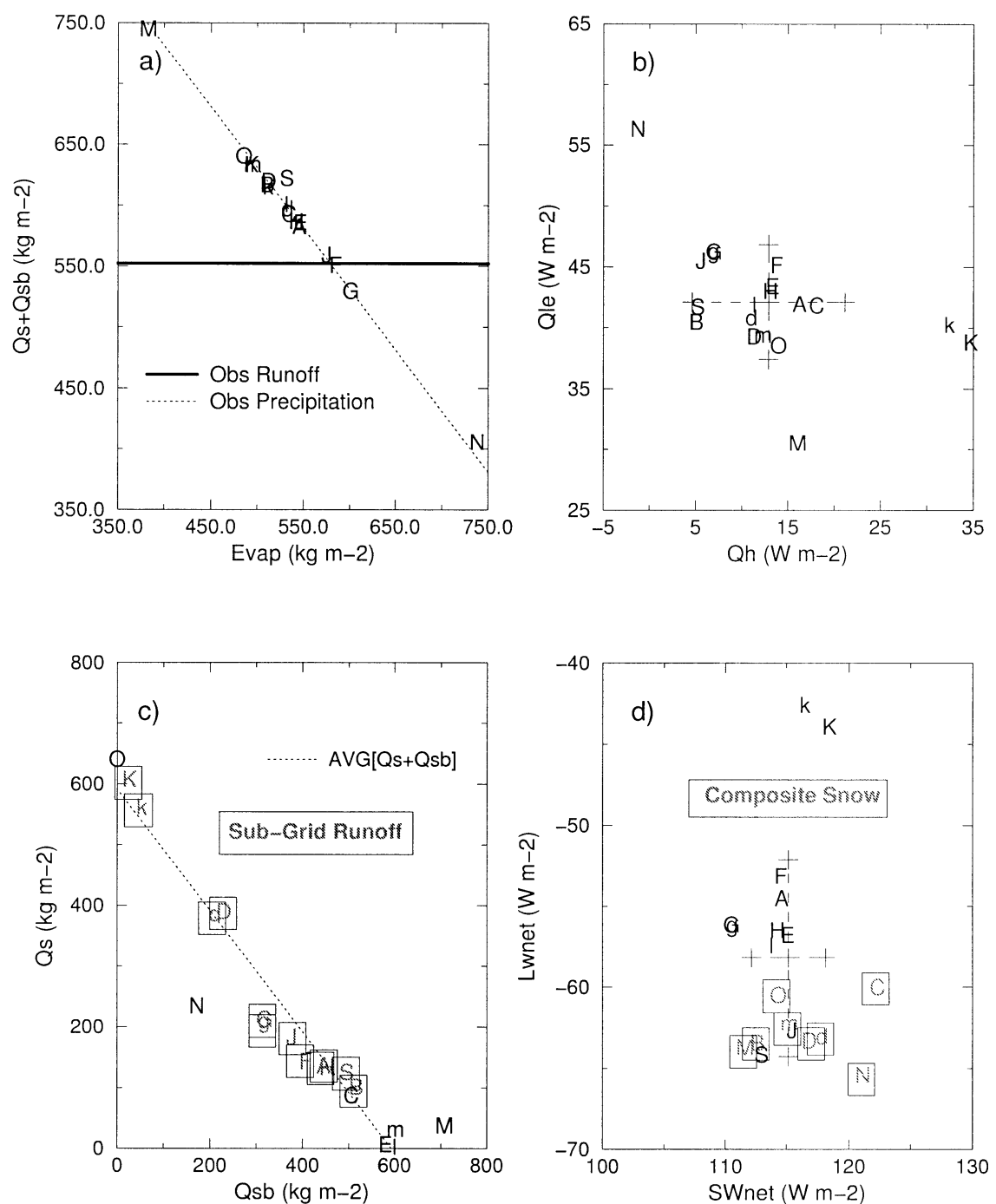

FIG. 4. The 3-yr basin-average surface fluxes and hydrological components for 20 LSS realizations. See Table 2 for the LSS IDs: lower case letters are reserved for reruns. The surface runoff (fast component), drainage flow runoff (slow), evapotranspiration, latent heat flux, sensible heat flux, net longwave radiation, and net shortwave radiation are represented by Qs, Qsb, Evap, Qle, Qh, LWnet, and SWnet, respectively. (a) The total observed precipitation is shown as a reference. (c) The LSS average total runoff (Qs+Qsb) is shown, and the symbols for the LSSs using a subgrid runoff scheme are boxed. (d) LSSs using composite snow schemes (see section 4a for details) are boxed.

Approximately half of the simulated runoff totals fall within $\pm 10 \%$ of the observed runoff. The runoff overestimate seen in most models is likely related to significant water extraction from the Rhône near its outlet for irrigation and human consumption. An alternate upstream gauge is used for the more detailed discharge evaluation [see section $4 \mathrm{a}(4)$ ].

All but three LSSs fall within $\pm 10 \%$ of the modelaverage runoff; however, there is considerable intermodel scatter in terms of the partitioning (Fig. 4c). The ORCHIDEE and Chameleon Surface Model (CHASM) configurations for this study only generate runoff when the soil total water holding capacity is exceeded (the rest of the LSSs can generate Qs or Qsb at relatively lower soil water values). The majority of the LSSs simulate larger drainage than surface runoff, and LSSs with subgrid runoff generally have a Qs/Qsb ratio between 0.15 and 0.30 . It will be shown that this ratio is quite important for accurately simulating the daily discharge.

The partitioning of the simulated turbulent fluxes is shown in Fig. 4b, where the latent and sensible heat fluxes are represented by $\mathrm{Qle}$ and $\mathrm{Qh}$, respectively. The LSS average and standard deviations are shown using dashed lines. Note that the intermodel scatter is significant, but is comparable to what was obtained in other LSS intercomparison projects such as PILPS and GSWP. 

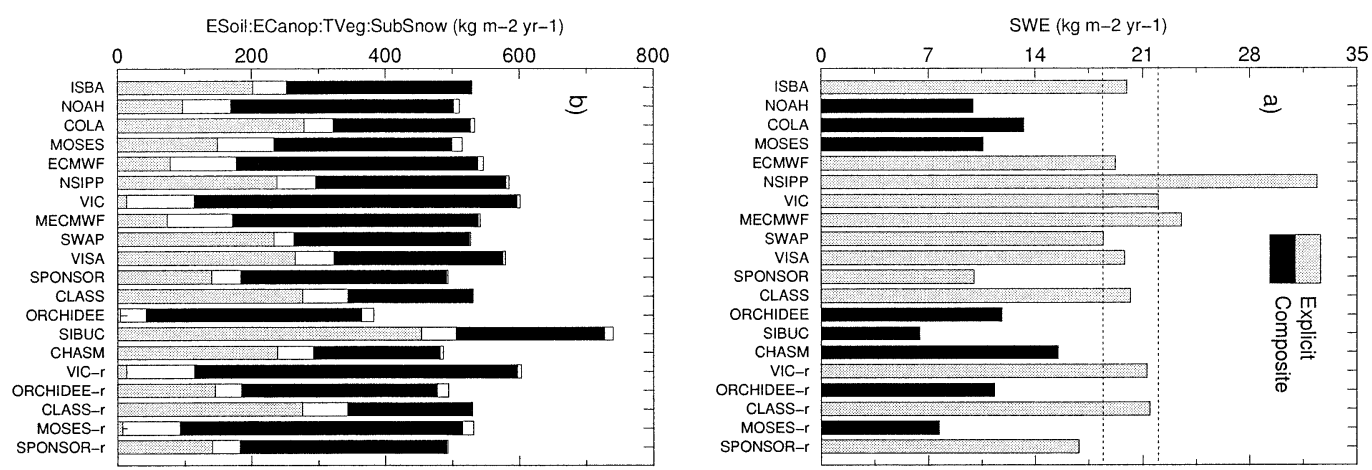

FIG. 5. The 3-yr basin-average snow water equivalent (SWE) and evapotranspiration components for 20 LSS realizations. From bottom to top of each bar: baresoil evaporation (gray), evaporation of intercepted canopy water (white), transpiration (black) and sublimation (white) are represented by ESoil, ECanopy, TVeg, and SubSnow, respectively.

Even though the average Qle among the tile and nontile LSSs is approximately the same, the intermodel scatter in Qle among effective LSSs is very small, with eight simulations falling within $4 \mathrm{~W} \mathrm{~m}^{-2}$ of each other (approximately $10 \%$ of the average Qle value). The Qle scatter is larger among tile schemes, but differences in model formulation seem to be more critical than whether or not a multiple-versus single-tile scheme is used. As an example, the two LSSs that submitted results for both tiled and nontiled approaches (CLASS and MOSES), have minimal Qle and Qh differences (far less than the inter-LSS scatter).

The net radiation balance components are shown in Fig. 4d, where SWnet and LWnet represent the net shortwave and longwave radiative components, respectively. The surface albedo is prescribed, but there is some SWnet scatter owing primarily to differences in fractional snow-cover area between the models (and some LSSs, such as COLA and SIBUC, diagnose the vegetation albedo). Surface emissivity is prescribed along with the atmospheric longwave forcing, so that LWnet scatter is caused by differences in the simulated surface temperature. Note that LSSs using composite snow schemes produce larger longwave energy fluxes [see section $4 \mathrm{a}(3)$ for more details].

The simulated 3-yr basin-averaged SWE and evapotranspiration components are shown in Figs. 5a and 5b, respectively, where the LSS reruns are indicated using an "-r" extension. Snowfall is not a source of intermodel scatter among 12 LSSs as they used the prescribed forcing. Center for Ocean-Land-Atmosphere Simple Biosphere Model (COLA) and Simple Biosphere Model Including Urbar Canopy (SIBUC) partitioned total precipitation into rain and snow using the air temperature, resulting in a $24 \%$ and an $18 \%$ reduction in snowfall, respectively. This partitioning is an inherent part of the snow scheme physics for these LSSs and could not be changed for Rhône-AGG. VIC also used a partitioning based on a prescribed lapse-rate parameter. In its original run, the standard value for this parameter resulted in an overestimation of snowfall. The reduced value (for the rerun) resulted in snowfall that is more consistent with the provided forcing. The SWE varies considerably between LSSs, due to different melting rates and descriptions of liquid water in the snowpack. Note that $40 \%$ of the LSSs simulate SWE within a relatively narrow range (the boxed area in Fig. 5a), and all of these are explicit snow schemes. This aspect of the LSSs will be discussed in more detail in section $4 \mathrm{a}(3)$.

The four evapotranspiration components are shown in Fig. 5b, where evaporation from bare soil, evaporation from water intercepted by the canopy, transpiration, and sublimation are represented by ESoil, ECanop, TVeg, and SubSnow, respectively. Sublimation is quite small for all of the LSSs, which is in contrast to results obtained by PILPS-2e over an arctic basin (Nijssen et al. 2002). This is most likely related to the generally warmer and moister air, to lighter winds and smaller snow-cover extents. The partitioning among the remaining evaporative components is variable among the schemes, although ESoil and TVeg together comprise between $80 \%$ and $94 \%$ of the total evapotranspiration for all of the LSSs. Despite the fact that the LSSs use the provided vegetation cover fraction (which is generally used to parition evapotranspiration between soil and vegetation), large differences in the ratio ESoil/ (TVeg +ESoil) are found. As already thoroughly discussed in previous PILPS exercises, the difference in partitioning is primarily due to the widely varying bare soil evaporation parameterizations (Desborough et al. 1996) and the water-stress-related transpiration relationships [water-stressed canopy resistance: Mahfouf et al. (1996); root-zone profile formulations: Desborough (1997)].

\section{2) SoIL MOISTURE}

The soil moisture is a key LSS variable, as it controls the partitioning of incoming energy into turbulent fluxes (for partially covered or snow-free surfaces) and the near-surface hydrology. The soil wetness index (SWI) 

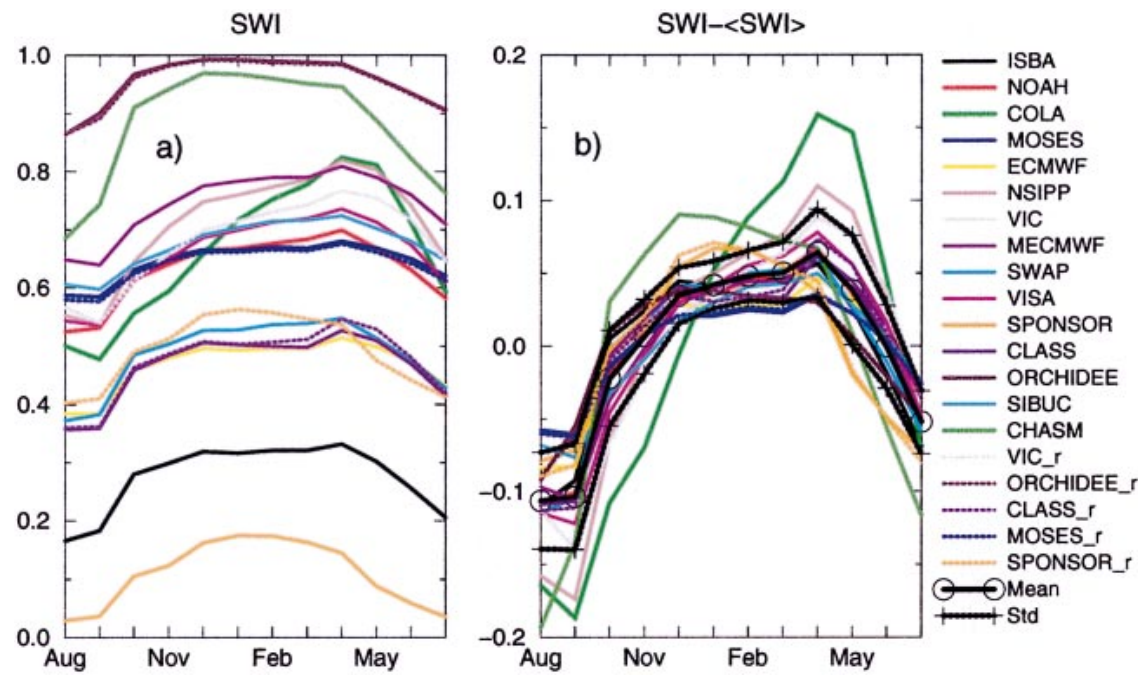

FIG. 6. (left) The 3-yr basin-average monthly soil water index (SWI) for all LSS realizations. (right) The SWI scaled by the corresponding LSS annual average value, or SWI', along with the monthly LSS average and standard deviation.

is a normalized measure of the soil water content. It is defined as

$$
\mathrm{SWI}=\frac{W /\left(d_{\text {soil }} \rho_{w}\right)-w_{\text {wilt }}}{w_{\text {max }}-w_{\text {wilt }}} \quad(\mathrm{SWI} \leq 1),
$$

where $W$ represents the total soil water content $\left(\mathrm{kg} \mathrm{m}^{-2}\right)$ for the layer thickness $d_{\text {soil }}(\mathrm{m}), \rho_{w}$ is the density of liquid water, and $w_{\text {wilt }}$ represents the wilting point volumetric water content $\left(\mathrm{m}^{3} \mathrm{~m}^{-3}\right)$. The maximum volumetric water content $\left(w_{\max }\right)$ is equivalent to the porosity $\left(w_{\text {sat }}\right)$ for all of the schemes but two, ORCHIDEE and CHASM, which assume $w_{\max }=w_{\mathrm{fc}}$. Values of total soil depth $\left(d_{\text {soil }}\right)$ for each LSS are listed in Table 4.

The 3-yr monthly domain-average soil wetness index for each of the LSSs is shown in Fig. 6a. The SWI spread is significant as each LSS converges to a schemedependent equilibrium state or "effective field capacity," which is related to the interplay between evapotranspiration and runoff within each LSS (Koster and Milly 1997). Consistent with the findings of Entin et al. (1999) for the GSWP-1, there is almost no agreement between schemes in terms of average soil moisture (values range from roughly 0.1 to $1.0 \mathrm{~m}$ for the LSSs that use approximately the same holding capacity) despite the relatively small range in basinwide total annual evapotranspiration and runoff.

Some of the differences can be explained based on a simple examination of scheme physics. ORCHIDEE and CHASM have considerably smaller soil water holding capacities than the other schemes and little to no water loss outside of periods with snowmelt or rainfall, so that SWI values can readily approach a value of 1 ; whereas in most schemes saturation is rarely achieved, primarily owing to the rapid removal of soil water by drainage under moist conditions.
In contrast, the Modified ECMWF Scheme (MECMWF) LSSs have the largest holding capacities. ECMWF assumes spatially constant values of $X_{\text {clay }}$ and $X_{\text {sand }}$ (loam), which corresponds to a coarser (and betterdrained soil) than the Rhône basin average. Indeed, ECMWF has among the lowest average SWI values. MECMWF uses the van Genuchten (1980) hydraulic parameter model for six soil classes. This model tends to result in lower hydraulic conductivities and greater water retention than those of the provided parameter sets for the same soil textures, resulting in one of the largest average SWI values. The contrast between MECMWF and ECMWF is significant as they use the same surface energy budget formulation and soil layering.

ISBA is among the driest LSSs, but as opposed to most of the LSSs, which use a discretized form of Richard's equation for vertical soil water transfer, ISBA uses a rapid relaxation to a field capacity parameter based on the water content in a $1-\mathrm{m}$ soil column assuming hydrostatic equilibrium at a hydraulic conductivity of $0.1 \mathrm{~mm} \mathrm{day}^{-1}$ (Mahfouf and Noilhan 1996). The corresponding basin-average SWI of this value is 0.30 , which is the approximate SWI value for ISBA during periods of low evaporative demand.

The annual average SWI is removed from each scheme and the results (called SWI') are shown in Fig. $6 \mathrm{~b}$, along with the SWI' average and standard deviation over all LSSs for each month. Overall, the basin-scale SWI' tendencies (and therefore water storage changes) are similar, with the largest intermodel scatter occurring in late summer (primarily because of differences in evapotranspiration parameterizations), and late winterearly spring (owing to differences in runoff and snowmelt). After the models have spun up, it is the difference 
SWI Range (Monthly)

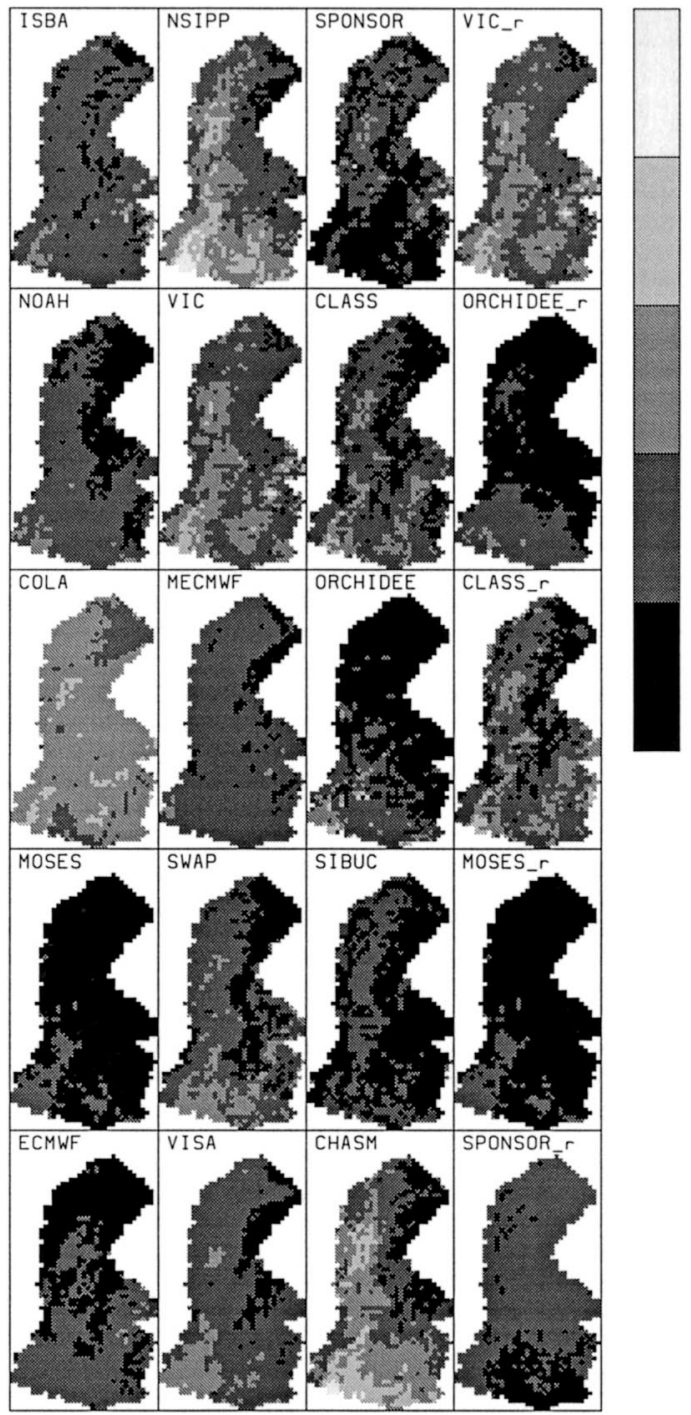

FIG. 7. The 3-yr average maximum range in monthly average SWI' at each grid point.

in the change in soil water storage that is important to explain intermodel differences in terms of hydrology.

The maximum range in the 3-yr monthly averaged SWI is shown at each grid point in Fig. 7. This is similar to what is shown in Fig. 6a, except that the difference between the maximum (late winter-early spring) and minimum (late summer) monthly SWI values are shown at every grid point. The SWI range is generally largest in the south near the mouth of the Rhône and along the Rhône valley (where evaporative demand is the largest), and it is generally the smallest over the north and the eastern mountain ranges (primarily due to significant precipitation, snow cover, and lower radiative energy input). Eleven LSSs have a liquid water holding capacity of $w_{\text {sat }} d_{\text {tot }}$, so that the comparison of their SWI range is more straightforward. The three of these LSSs that have largest surface-to-total runoff ratio [Qs/(Qs + Qsb)] have among the lowest overall SWI ranges and spatial variability of this range (MOSES, SIBUC, and SPONSOR). For these LSSs, a larger surface-to-total runoff ratio results in lower infiltration and drainage, while evapotranspiration is impacted to a lesser degree (SWI peaks are lower than those of the other LSSs, while minimum values are similar, therefore reducing the range). The LSS with one of the lowest soil water holding capacities, CHASM, has relatively large spatial variations as the entire range in SWI is attained more easily. ORCHIDEE has a similar maximum soil water content limit as CHASM $\left(w_{\mathrm{fc}}\right)$, but the lower soil water limit is less, which results in lower spatial variability in the range in SWI. NSIPP has the largest domainaverage SWI' annual cycle amplitudes (Fig. 6b), and a much more varied spatial pattern (Fig. 7). NSIPP differs in concept from the other LSSs in terms of its hydrology: Three separate moisture regimes are defined (each with a separate evapotranspiration estimate) which vary in spatial coverage as a function of topographic index and average soil moisture at each time step (for more details, see Koster et al. 2000). The large range in SWI at the mouth of the Rhône corresponds to the zone of highest atmospheric evaporative demand, and two schemes that assume a saturated surface fraction for evaporation (VIC and NSIPP) have the largest ranges in this region.

\section{3) SNOW DEpth Evaluation}

A comparison between the observed and the simulated snow depths is shown in Fig. 8, where both the observations and the simulations are averaged over 24 sites and for three annual cycles. The statistics are calculated over a 3-yr period using daily average snow depths at each site that are compared to grid-box average LSS snow depths. Most observations cease at the end of April at the closure of ski resorts, and after April, the observations correspond to a single high-altitude research site $(2450 \mathrm{~m}$; the grid box average altitude is $2459 \mathrm{~m})$.

The overall statistics are found to be generally consistent with the type of scheme (summarized in the third column of Table 4). Explicit schemes tend to perform the best statistically: ISBA, SWAP, CLASS and VISA all have rms errors less than $0.3 \mathrm{~m}$, biases less than 0.07 $\mathrm{m}$, and squared correlation coefficients greater than 0.71. Three LSSs use three-layer snow schemes, and two of them (ISBA and VISA) have the most similar statistics of all the LSSs. But overall, little distinction can be made between the bulk and multilayer explicit schemes in terms of statistics. All but one of the explicit schemes have rms errors less than $0.4 \mathrm{~m}$. In contrast, only one composite scheme (CHASM) has rms errors less than 0.4 .

A clear distinction can be made between these two snow scheme types based on simulated SWE. Overall, explicit schemes simulate approximately twice the ba- 
Average Snow Depth at 24 Alpine Sites over 3 years

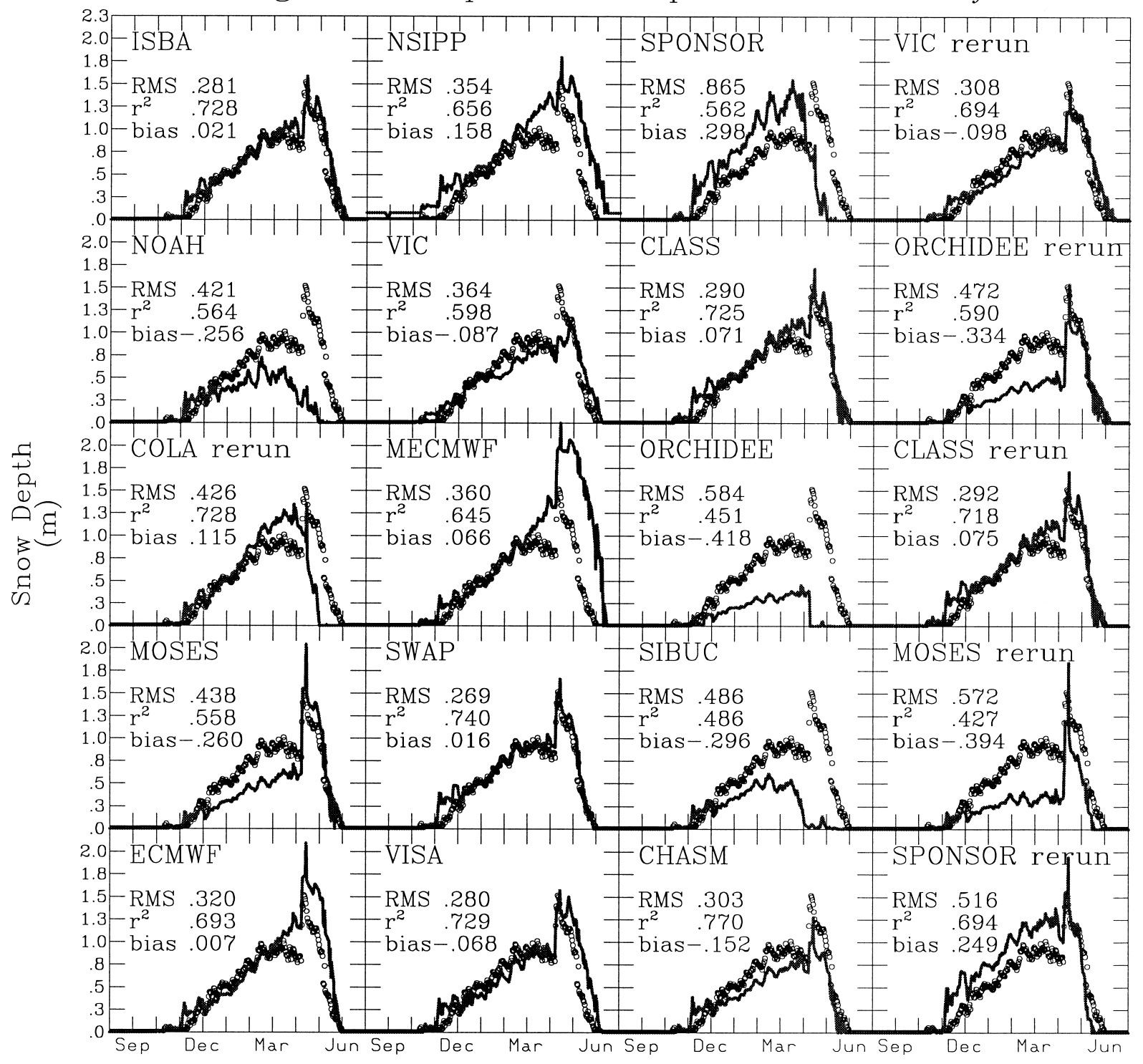

FIG. 8. The observed (circles) and simulated (solid line) snow depth for 20 LSS realizations. The annual cycle averaged over 3 yr is shown. The data points and simulations are averaged over the 24 sites: the statistics are calculated over all of the sites over 3 yr at approx 1-day intervals. The root-mean-square error (rms in $\mathrm{m})$, squared correlation coefficient $\left(r^{2}\right)$, and the bias $(m)$ are shown.

sinwide annually averaged SWE of the composite schemes (Fig. 5a). All composite schemes simulate values less than $16 \mathrm{~kg} \mathrm{~m}^{-2}$, while only one explicit scheme produces a value lower than this threshold. It should also be noticed that if for two of the composite schemes (COLA and SIBUC) the SWE values are increased by the difference between their snowfall and the SAFRAN analysis, their predicted SWE would still be lower than that of the explicit schemes (except perhaps one). The early snowmelt resulted in reduced snow area coverage in time and space, leading to annually averaged dryer and warmer mountain zones for composite schemes. This impact can also be seen in terms of the reduced LWnet (Fig. 4d).

There are two main problems found with the composite schemes for the current study that resulted in a too-early ablation. First, none of them included the ripening mechanism (i.e., the incorporation of meltwater and rainfall into the snow cover; $\mathrm{R}$ in Table 4), which can significantly increase the SWE (owing to the deep snowpacks) and extend the snowmelt runoff (Boone and Etchevers 2001). It also has a significant impact on both 

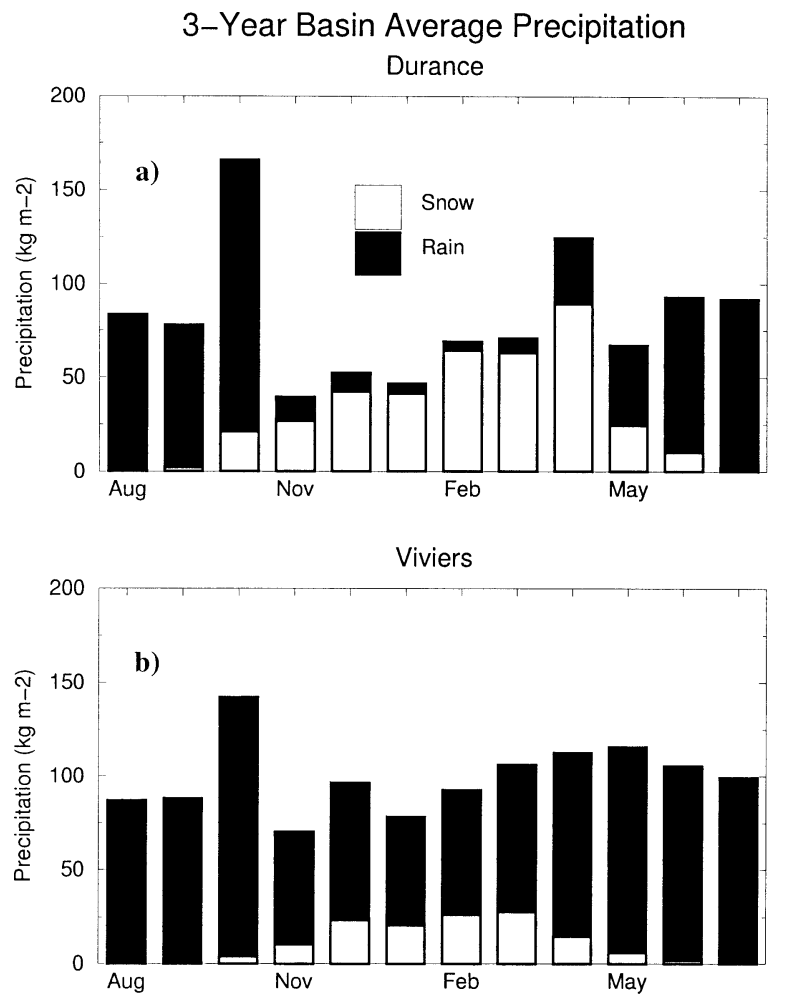

FIG. 9. The observed 3-yr average total monthly rain and snowfall for (a) the Durance at Laclapière and (b) the Rhône at Viviers. The corresponding basins have surface areas of $2170 \mathrm{~km}^{2}$ (Durance), and over 61000 km² (Rhône).

the volume and timing of the simulated discharge in mountainous river basins within the Rhône basin (Etchevers 2000). The second problem seems to be related to properties of the snow-soil mixture having a larger albedo and a different thermal conductivity compared to a pure snow surface.

\section{4) Discharge evaluation}

Model statistics are calculated for 145 basins, but results are presented for only 2 of them. A more detailed analysis of the remaining basins will be presented in a forthcoming paper. The 3 -yr average monthly total rain and liquid water equivalent snowfall are shown for the Durance at Laclapière and the Rhône at Viviers in Figs. $9 \mathrm{a}$ and $9 \mathrm{~b}$, respectively. The simulated and observed monthly mean discharge averaged over 3 -yr are shown for all LSS realizations for the Rhône and the Durance in Figs. 10 and 11, respectively. The locations of these gauging stations are shown in Fig. 1. Viviers is selected as a surrogate for the Rhône basin instead of Beaucaire as there is a great deal of water extraction along the Rhône below Viviers, and because the Durance River is greatly influenced by dams below Laclapière (and it is a major tributary of the Rhône just above Beaucaire). Unfortunately these impacts have yet to be included in the database, so that a more reasonable model evaluation over a large portion $(81 \%)$ of the basin can be done using data from Viviers. Note that Laclapière is at the mouth of a high-altitude basin (over 2000-m mean elevation) for which most of the precipitation falls as snow (Fig. 9a).

Statistics are shown in each square of Figs. 10 and 11 for each LSS using the monthly discharge (left column) and daily discharge (right column), where Eff represents the efficiency or Nash criteria (Nash and Sutcliffe 1970), and Ratio represents the simulated discharge divided by the observed value. The coefficient Eff measures the skill of the model at capturing the observed variability. One is a perfect score, an Eff of zero means that the model is capable of representing the observed temporal mean, and $* * * *$ is used to indicate a negative value (i.e., a poor simulation).

The total streamflow volume at Viviers is well simulated by most of the LSSs: $70 \%$ of the 20 realizations are within $\pm 5 \%$, and $85 \%$ are within $\pm 10 \%$. At this location, there is no consistent LSS bias (as is the case at Beaucaire; Fig. 4a), since the discharge is underestimated by nearly half $(45 \%)$ of the LSSs. Note that, however, the LSSs perform quite differently in terms of the monthly and daily statistics.

In terms of daily statistics at Viviers, six LSSs produce very good results in terms of Eff $(\geq 0.7)$, while three give reasonable results $(0.7 \geq$ Eff $\geq 0.5)$. Seven of these nine LSSs use subgrid runoff schemes (Table 4). The Eff is highly sensitive to large amplitude differences, and this type of error prevails for large storm pulses, which are dominated by the fast-response runoff component (Qs). Note that the runoff ratios (SRRs; ratio of surface runoff to total runoff) shown in Fig. 4c for the entire Rhône basin are similar to those for the Viviers. The only three LSSs with Eff values $\geq 0.8$ simulated SRR values of 0.12-0.25. In general for the LSSs, the larger the simulated SRR (above 0.25), the worse the Eff for this basin (e.g., the six LSSs with SRRs $>0.5$ all had Eff values $<0.2$ ).

The ECMWF and CLASS schemes simulate good daily Eff values for Viviers even though they do not have subgrid runoff schemes $(0.75 \leq$ Eff $<0.80)$. This results because of increased infiltration (due to the reduced Qs), so that drainage is comparatively larger and responds more rapidly to precipitation (because the soils are nearer to their holding capacities). In addition, there is a very large amount of outflow at this gauge (the drainage area spans most of the Rhône basin) so that the response to local smaller-scale precipitation events is somewhat damped. The modeling of fast-response flow becomes more critical for smaller basins. For example, in the Saone basin (see Fig. 1), the three LSSs with the best Eff values (0.7-0.8; the same LSSs as for Viviers) simulate SRRs between 0.10 and 0.25 , while CLASS and ECMWF Eff values range between 0.5 and 0.6. As is the case for Viviers, the LSSs with large SRRs $(>0.5)$ have much lower Eff values.

Simulating a reasonable surface-runoff ratio is critical 


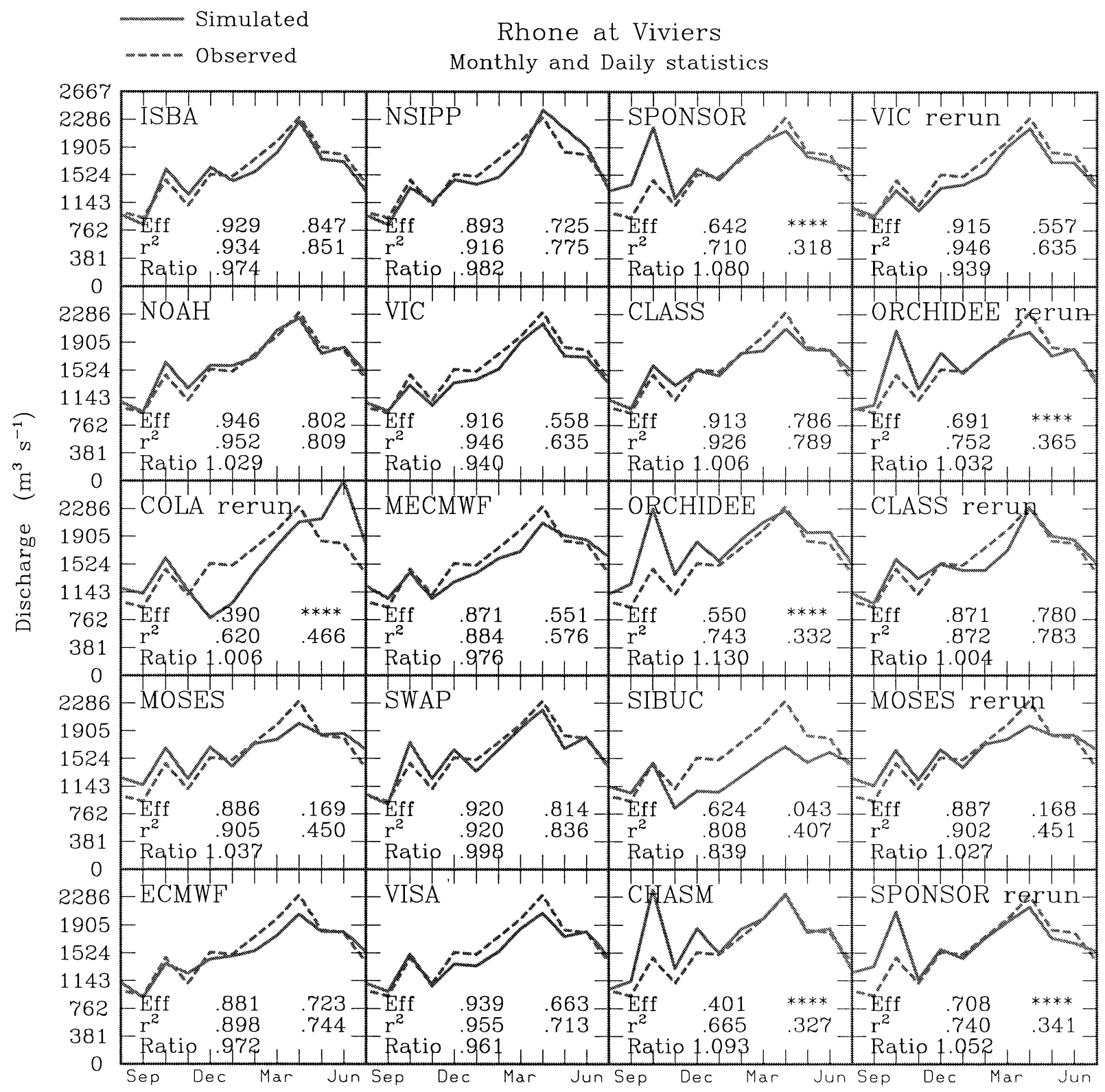

FIG. 10. The observed (dashed) and simulated (solid line) monthly river discharge for 20 LSS realizations for the Rhône at Viviers (see Fig. 1 for the location). The annual cycle averaged over $3 \mathrm{yr}$ is shown. For the statics (left) The monthly and (right) daily efficiency coefficient (Eff), squared correlation coefficient $\left(r^{2}\right)$, and the ratio of the simulated to the observed discharges (Ratio) are shown. A negative efficiency value is indicated using $* * * *$.

for good daily discharge scores, while it is less critical for a good monthly score for Viviers. As an example, MOSES and SPONSOR have very large SRRs compared to other LSSs and the daily Eff is much lower than the monthly value. The MECMWF LSS has statistical values that are nearly identical to the ECMWF scheme on the monthly timescale, but far worse at the daily timescale. This is related to two causes. First, the subgrid surface runoff tends to be a bit too strong (as discussed above, statistically it is better to underpredict surface runoff than to overpredict it). Second, the Van
Genuchten parameters for this basin result in greater water retention in the soil column compared to those provided and a more slow (than observed) drainage response (for the given soil depths and textures). ORCHIDEE and CHASM have lower water holding capacities so that little of the large autumnal rainfall (see Fig. 9b) is used for soil water recharge compared to the other LSSs, resulting in an overestimation of runoff. In addition, runoff only results as an instantaneous response to precipitation and snowmelt in these schemes so that Eff scores tend to be low. 


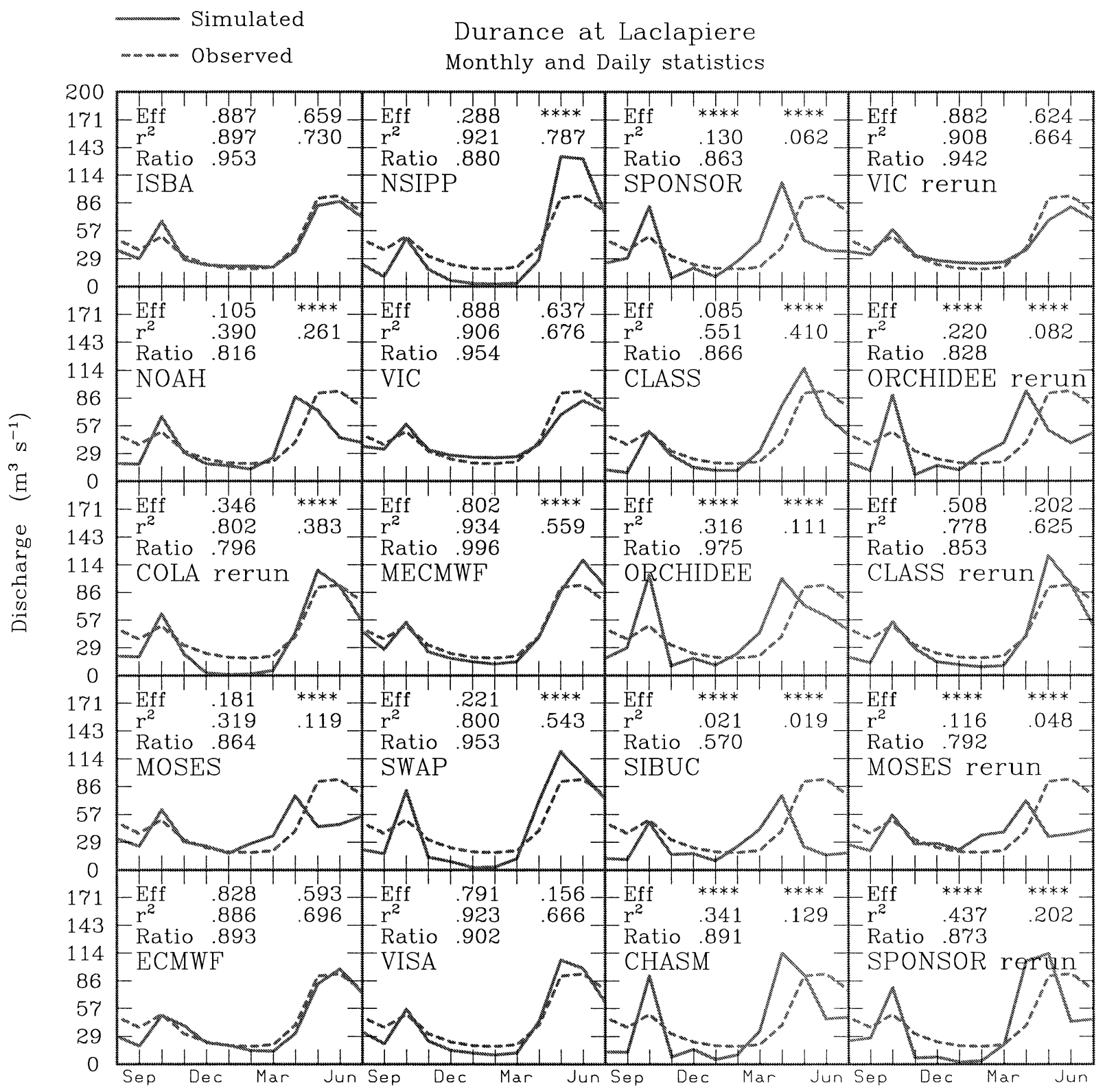

FIG. 11. As in Fig. 10 except for the Durance at la Clapière.

It is noteworthy to mention that despite the fact that several schemes use the same methods to generate subgrid runoff (see the last column of Table 4), they simulate contrasting runoff responses. ISBA and VIC use the VIC method, but use different basinwide values of the subgrid surface-runoff parameter $(0.2$ and 0.1 , respectively). The larger value should produce a higher surface-runoff ratio for ISBA, but in fact, VIC produces a consistently higher ratio. NSIPP and VISA use the TOPMODEL (Beven and Kirby 1979) methodology (and the same topographic indexes), but the implementations (and other primary parameter values, such as the hydraulic conductivity decay factor) are different (see Koster et al. 2000; Yang and Niu 2002). The soil mois- ture evolution equations, evapotranspiration methodologies and differences in drainage/baseflow result in large runoff response differences, which can exceed those caused by parameter value differences.

The Durance basin turns out to be much more challenging for the LSSs due to its significant snowfall (see Fig. 9a): The correct simulation of the snowmelt peak is critical for estimating the discharge. Only five simulate a positive value of Eff for the Durance at the daily timescale (Fig. 11), and only three of these LSSs simulate reasonable values $(\geq 0.5)$. All five of these LSSs have among the best snow simulations and are explicit snow schemes. Peak spring discharge (most of which results from snowmelt over this basin) tend to occur 3- 
4 weeks early for composite schemes, which is consistent with their lower basinwide annual average SWE (Fig. 5a). Along with an accurate snow-cover simulation, the simulation of sufficient baseflow during the winter is also critical as it prevents the spring melt discharge amplitude from being too large (e.g., ISBA, ECMWF, VIC). Total flow volume is underestimated in all of the realizations, however, the two LSSs with the best overall Eff values simulate the total discharge to within $6 \%$ of the observed value. Explicit snow schemes generally simulate larger total flow volumes than composite ones because spring and early summer evapotranspiration are less due to a longer duration snow cover.

\section{b. Impact of scaling}

A linear operator is used to aggregate the control atmospheric forcing fields to the $1 / 2^{\circ}(\operatorname{Exp} 2 b)$ and $1^{\circ}$ (Exp2a) grid configurations. In the aggregated forcing, however, the control frozen precipitation rates are conserved, so that it is possible to have snow falling at warmer air temperatures than in the control case (i.e., about $0.5^{\circ} \mathrm{C}$ ). This also implies that the two LSSs using a temperature threshold to determine this partitioning (COLA and SIBUC) have less snowfall as the spatial scale increases (as the average air temperature will increase over the mountains due to the inclusion of the atmospheric state of lower-altitude regions).

The impact of upscaling the surface parameters and atmospheric forcing on the surface turbulent fluxes and the main hydrological components for all of the LSS simulations is shown in Fig. 12. The relative difference for a particular variable is defined as the ratio of the value for the experiment of interest less the ratio of the control value (Expl) divided by the control value, and the scaling-experiment labels are shown along the abscissa. Note that the values for each experiment are calculated as averages in time and over the entire basin. The relative differences are plotted with increasing spatial scale from left to right. The absolute differences in the evaporation and runoff components between Exp2a and 1 are shown in Fig. 13.

The relative differences for the latent (Qle) and sensible (Qh) heat fluxes are shown in Figs. 12a and 12b, respectively. The Qle differences tend to be small at the $1 / 2^{\circ}$ scale, with an average of approximately $3 \%$ for all LSSs, with most LSSs having differences of $6 \%$ or less. Most LSSs have a very similar response to upscaling to $1^{\circ}$ : the average LSS error climbs to approximately $4 \%$, with most schemes having differences of $8 \%$ or less. The slope of the trends is similar among most LSSs for Exp2b and 2a. NSIPP is the only LSS with a significant decrease in Qle with upscaling (see later for more details).

The intermodel scatter of the relative impact of upscaling Qle is due to differences in the interpretation of the various vegetation parameters within each scheme and the partitioning of the evaporative and runoff components. The impact of scaling on each vegetation parameter within every LSS is complicated and beyond the scope of this study, but a partial explanation can nevertheless be given by examining the LSS Qle components (Figs. 12b,d,f,g,h). The Qle increases are due to increases in ECanop and ESoil in most of the LSSs. The increase in ECanop is a classic response to aggregated precipitation (e.g., Dolman and Blyth 1997) owing to "precipitation smearing": the rates are generally reduced and the spatial coverage of an event is increased by an upscaling average. This also implies relatively drier atmospheric conditions with larger solar radiation and air temperatures coinciding with rain events in aggregated grid boxes (thus increasing the atmospheric demand, especially during the spring, summer, and early autumn).

ECanop increases by an average (for all LSSs) of approximately $15 \%$ for the $1 / 2^{\circ}$ scale, and $30 \%$ for the $1^{\circ}$ scale, and these changes are the most consistent among the LSSs (Fig. 12d). This is significant as ECanop comprises less than $20 \%$ of the total basinwide evapotranspiration in all of the LSSs (see Fig. 5b), but it has a large sensitivity in the absolute sense (a significant of total Evap scaling response). Indeed, the response is more pronounced for all LSSs over forested zones (not shown). Scaling also invokes a similar but slightly less consistent (in magnitude) response in ESoil, which increases by approximately $4 \%$ and $8 \%$ when upscaling to $1^{\circ}$ (Fig. 12f). The increase in ESoil is related to larger near-surface soil moisture contents (as discussed later) and the increased evaporative demand. The impact of scaling on TVeg is less consistent, with a LSS average relative difference ranging between $\pm 3 \%$ for most LSSs. One LSS, NSIPP (F), has a ECanop response similar to that of the other LSSs, but both ESoil and TVeg decrease significantly with increasing scale. But as mentioned before, the response is more difficult to compare to that of other LSSs as the concept for hydrology is unique.

The sensible heat flux relative differences are shown in Fig. 12b. In general, schemes with the largest relative decreases in Qh due to scaling also experienced the largest increases in Qle, as most LSSs conserved the overall magnitude of the turbulent fluxes during scaling: the net radiative fluxes increased by less than $1 \mathrm{~W} \mathrm{~m}^{-2}$ or $1 \%-2 \%$ in all LSSs but one, and the corresponding ground heat flux changes are very small (not shown). The aforementioned, somewhat unique increase in Qle for NSIPP is offset by one of the largest increases in Qh. NOAH also has a significant increase in Qh, but the change with scale is less consistent, and it also has a significant increase in Qle. One of the main reasons for this rather unique response is its use of dominant parameters (as opposed to aggregated ones). This implies that surface types for a given surface area can change significantly with scale (a $1 / 2^{\circ}$ grid box might be composed of grassland, while the same area might 

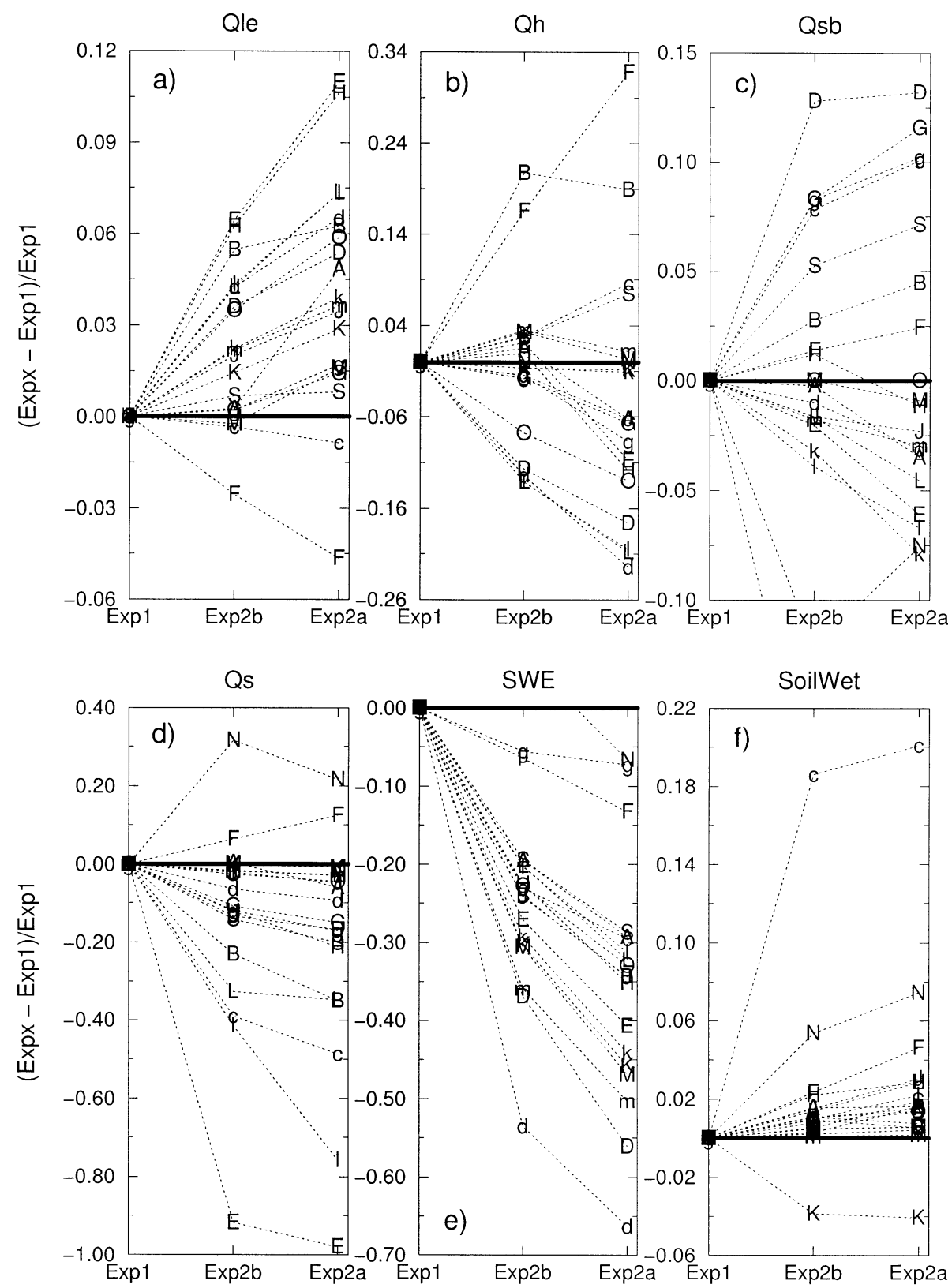

FIG. 12. The impact (as a relative difference) of scaling on selected LSS surface fluxes and hydrological components. The upscaled values are compared to the control, high-resolution results. Exp2b and Exp2a correspond with upscaling to $1 / 2^{\circ}$ and $1^{\circ}$ grids, respectively. Exp2c corresponds to using dominant surface parameters on a $1^{\circ}$ grid.

be forest for the $1^{\circ}$ grid), and that the vegetation parameters can be quite different from those of the other LSSs.

The surface runoff (Figs. 12d and 13c) is reduced in all LSSs but two as a function of increasing scale, although the magnitude of the impact varies greatly among the schemes. Note that the LSSs with the largest relative reductions do not have subgrid runoff and therefore the changes are not hydrologically significant (e.g., ECMWF). The general reduction in Qs (and correspond- ing increase in infiltration) is primarily related to aggregation of the precipitation that leads to less intense and more prolonged and widespread rainfall.

The interpretation of the Qsb response (Figs. 12c and $13 \mathrm{e})$ is more difficult as it is not only representative of the sum of the Qs, SWE, and Qle changes, but it also is changed by the scaling of the soil hydraulic parameters. Assuming all other factors are unchanged by the scaling, the aggregation of soil texture will tend to reduce drainage in most LSSs over regions with texture 
Exp2a-Exp1 (kg m-2)
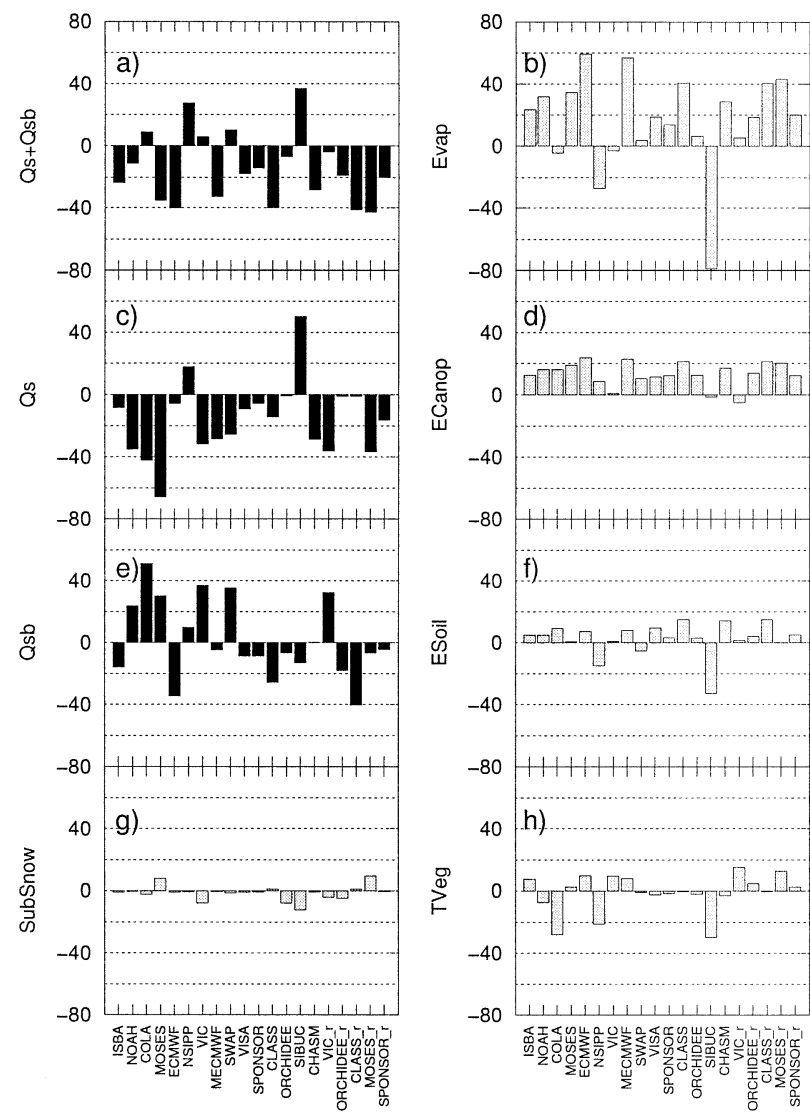

FIG. 13. The absolute differences between the $1^{\circ}$ (Exp2a) and control simulation for the evapotranspiration and runoff components.

heterogeneities as the impact of the most coarse soils are smoothed out (their influence tends to dominate the drainage; Wetzel et al. 1996). The net effect is slightly decreased total runoff in most LSSs (Fig. 12a).

The impact of scaling on SWE is shown in Fig. 12e, and a significant reduction is seen in all of the LSSs but one. The SWE changes are primarily related to the aggregated forcing: the relatively high-altitude cool subgrid zones tend to have warmer conditions (greater atmospheric temperature and longwave downwelling radiative forcing), while low areas experience the opposite effect. These effects are enhanced within grid boxes with significant subgrid topographic variability. The lapse rate/atmospheric forcing plays a critical role as the impact of scaling depends upon altitude: the impact on the three highest (and coldest) $1^{\circ}$ points is relatively small or negligible for nearly all of the LSSs (not shown). The VIC scheme, which is the least impacted by scaling, allocates altitude-dependent mosaic tiles when the subgrid variation in topography is sufficiently large, so that more snow falls in higher, colder regions at the expense of lower, warmer subgrid tiles/regions.

The scaling response to SoilWet (SWI) is shown in
Fig. 12f. All LSSs but one have moister soils, and the increases are fairly small in all but one of these LSSs (less than $3 \%$ at $1 / 2^{\circ}$ resolution, and less than $5 \%$ at $1^{\circ}$ ). The most important factor in most LSSs for the overall basin-average increase in soil moisture is the decreased surface runoff (an instantaneous response relative to the precipitation and snowmelt runoff). It results in more water cycling through the soil-plant system, thus raising the average soil moisture residence time (and therefore the average soil moisture). However, the LSSs still equilibrate to an effective field capacity similar to that in Expl, so soil moisture increases are relatively minor. Note that COLA simulated much higher rainfall rates (as the snowfall rate is diminished with increasing scale), which is contributing to a moister soil with increasing scale. SiBUC is also affected in the same manner, but to a lesser degree as the increase in rainfall is comparatively less [see section 5a (1)]. This shows that the snow/rain threshold temperature used in many LSSs should be increased in regions with relatively large subgrid topographic variability.

\section{Discussion and conclusions}

This paper presents a general overview of an evaluation and intercomparison of 20 realizations by 15 LSSs using a very high spatial resolution database of several annual cycles over the Rhône basin. Although the simulated energy budget and hydrological component intermodel scatter obtained in this experiment is typical of differences previously found in other LSS intercomparison studies (such as PILPS and GSWP), there are several important new results pertaining to scaling, subgrid runoff and modeled snow processes.

Most of the LSSs simulate very similar total runoff and evapotranspiration for three annual cycles, but the partitioning between the various components varies greatly, therefore resulting in very different soil water equilibrium states and simulated discharge. However, even though the simulated 3-yr average total soil moisture is significantly different between the LSSs (ranging from 0.1 to $1 \mathrm{~m}$ ), the monthly storage changes are similar when averaged over the entire basin. The spatial variability of the range in monthly average soil moisture is lowest over the mountains and the northern part of the basin due to snow cover and lower radiative energy for evaporation for most LSSs. LSSs generally have the highest spatial variability in the more water-stressed southern portion of the basin where the most significant inter-LSS differences occur: LSSs with saturated subgrid fractions have the largest spatial variability.

No significant systematic differences in the overall water budget or surface energy balance components in the control experiment can be attributed to the use of single tile versus multiple tiles except for snow cover. The difficulty in understanding this lack of difference arises, in part, because of contrasting multiple-tile scheme implementations: four of the nine LSS using tile 
options define a tile for each surface class, the remaining multiple-tile LSSs average parameters for similar surface types to conform to a maximum number of tiles (one LSS uses elevation bands, etc.). LSS physics (soil water stress and stomatal resistance, aerodynamic resistance, and surface energy budget/canopy parameterizations) seem to be causing most of the interscheme differences (as opposed to tiling) in this study.

The statistically best snow simulations, compared to data at 24 observation sites. are obtained by LSSs having so-called explicit snow schemes. The main reason is that these schemes consistently simulate larger SWE and snow depths than simpler so-called composite schemes, the explicit treatment of the snowpack thermal properties, and to the inclusion of certain key processes such as ripening. Two schemes treat snow cover using snow-covered subgrid tiles, while the other explicit LSSs treat snow cover as covering a subgrid portion of a tile or grid box.

The LSSs simulate the total flow volume and the monthly discharge at Viviers, which comprises over $80 \%$ of the total Rhône discharge, reasonably well on the monthly timescale. However, at the daily timescale, LSSs using subgrid runoff formulations generally perform better than schemes without subgrid runoff. Care must be taken with respect to subgrid surface runoff as an overestimation of this quantity is far more detrimental to the simulation accuracy than an underestimation. Only five of the LSSs are able to simulate the discharge with some skill on a monthly basis for a high Alpine basin (the Durance), all of them being explicit schemes and producing among the best depth simulations for the six observation sites within this basin. Composite snow schemes generally simulate too much snowmelt before the observed springtime discharge peak (peak runoff generally occurs 2-4 weeks early). Several schemes with good snow simulations do not simulate the discharge well due to an underestimation of wintertime baseflow runoff. For all of the basins, the LSSs that only permit runoff when the soil water is above the holding capacity (two LSSs; therefore there is no slow runoff component) or those which simulate most of the runoff as fast-response or surface runoff (three LSSs) generally did not simulate the daily discharge as well as the other LSSs for the Rhône subbasins.

The magnitude of the response of LSSs to upscaling varies greatly among models, although the trends tend to be similar for most schemes. Several basin-averaged quantities scale reasonably well, such as Qle and Qsb, with total relative differences generally less than $10 \%$ when moving from $8 \mathrm{~km}$ to $1^{\circ}$ (approximately $69 \mathrm{~km}$ ). Qle increases are most consistently a result of upscaling the forcing on ECanop, although ESoil also increases in most schemes (but to a lesser degree and with a less consistent response). Surface runoff is significantly decreased in most LSSs primarily because of the upscaling of the precipitation forcing. This result emphasizes the need for implementation of subgrid precipitation algorithms in large-scale LSS applications.

Soil moisture scales very well (to within $5 \%$ at the $1^{\circ}$ resolution for 13 of the $15 \mathrm{LSSs}$ ) because evaporation changes are generally offset by runoff changes with the opposite sign. The LSSs tend to equilibrate to soil moisture values, which are modulated by the parameterizations of runoff and evapotranspiration. It should also be noted that the LSSs generally simulate considerable soil moisture variability at the $8-\mathrm{km}$ resolution within each $1^{\circ}$ grid box, but the overall average is well conserved. The $1^{\circ}$ grid boxes that scale the worst are generally those with significant snow cover.

The SWE is the variable the most strongly affected by scaling: SWE is reduced in 13 of the $15 \mathrm{LSSs}$ by $25 \%-60 \%$ when moving to a $1^{\circ}$ resolution. This sensitivity is the smallest for the highest grid points in all of the LSSs, so that the sensitivity is directly related to the atmospheric forcing/altitude. Thirteen of the 15 LSSs used approximately the same total snowfall as in the control experiment, so the decrease in SWE resulted in earlier ablation as a consequence of the relatively warmer atmospheric forcing over snow-covered areas (i.e., regions with the largest topographic variability). This effect is consistent with what a GCM might simulate relative to a higher-resolution atmospheric model or a dense observational network. The only scheme that explicitly considers subgrid elevation effects on the forcing (VIC) minimizes the impact of scaling on SWE. The need for a better treatment of snow-cover dependence on spatial scale is warranted, especially as the interest in modeling river outflows using GCMs and coupled ocean-GCM models increases.

The results presented in this study apply to a single large basin over a relatively short time period (precluding the examination of interannual variability) and in offline or forced mode. Results relating to intermodel scatter may be different in a coupled-atmosphere model run, although studies such as those by Zhang et al. (2001) using a fully coupled LSS-GCM model have shown similar surface flux scatter because of changes in LSS parameter values or physics. But the conclusions regarding the impacts of scaling on runoff (especially subgrid surface runoff), turbulent flux partitioning, soil moisture and SWE (both scaling and complexity) should provide a strong motivation for LSS developers to address such scaling issues in their models. At the very least, this work could serve as a guide for helping the interpretation of results when a LSS is applied over a wide range of spatial scales. This is especially important as many atmospheric models continually move towards higher spatial resolutions (while retaining the same LSS).

Finally, the number of experiments used to investigate the scaling issue is limited in this study due to the large amounts of output data generated and the intensive computational resources required. Many more experiments could be envisioned in order to investigate scaling in a 
more rigorous manner (e.g., using scaled forcing with nonscaled parameters for the control grid, and vice versa, using more intermediate spatial scales), but this study is already a first step towards a greater understanding of scaling effects in LSSs.

Acknowledgments. The authors would like to thank all their colleagues at the many French laboratories that have participated in the development of the Rhône modeling system (BRGM, CEMAGREF, CETP, CIG, LTHE, Météo-France/CNRM and CEN). This work was supported by the Programme National d'Etude du Climat (PNEC; National Climate Study Programme), and by the Program National de Recherches en Hydrologie (PNRH; National Program for Hydrological Research). IFEN, INRA, the Banque Hydrologie, the French Environment Ministry and Météo-France provided the land cover, soil, river flow, and atmospheric databases. Two anonymous reviewers contributed significantly to the improvement of this paper. The intercomparison study was made possible by support from CNRS and GEWEX/WCRP. Participants representing the SWAP and SPONSOR LSSs were supported by the Russian Foundation for Basic Research Grants 02-05-64213 and 0105-64707, respectively. This project was completed while the lead author was at Météo-France/CNRM.

\section{REFERENCES}

André, J. C., J. P. Goutorbe, and A. Perrier, 1986: HAPEX-MOBILHY: A hydrologic atmospheric experiment for the study of water budget and evaporation flux at the climatic scale. Bull. Amer. Meteor. Soc., 67, 138-144.

Avissar, R., and R. A. Pielke, 1989: A parameterization of heterogeneous land surfaces for atmospheric numerical models and its impact on regional meteorology. Mon. Wea. Rev., 117, 21132136.

Beljaars, A. C. M., and F. C. Bosveld, 1997: Cabauw data for the validation of land surface parameterization schemes. J. Climate, 10, 1172-1193.

Beven, K. J., and M. J. Kirby, 1979: A physically-based variable contributing area model of basin hydrology. Hydrol. Sci. Bull., 24, 43-69.

Blyth, E. M., 2002: Modelling soil moisture for a grassland and a woodland site in south-east England. Hydrol. Earth Syst. Sci., 6, 39-47.

Boone, A., and P. Etchevers, 2001: An intercomparison of three snow schemes of varying complexity coupled to the same land-surface model: Local scale evaluation at an alpine site. J. Hydrometeor., 2, 374-394.

Bowling, L. C., and Coauthors, 2002: Simulation of high latitude hydrological processes in the Torne-Kalix basin: PILPS Phase2(e), 1: Experiment description and summary intercomparisons. Global Planet. Change, 38, 1-30.

Champeaux, J. L., D. Acros, E. Bazile, D. Giard, J. P. Gourtorbe, F. Habets, J. Noilhan, and J. L. Roujean, 2000: AVHRR-derived vegetation mapping over western Europe for use in numerical weather prediction models. Int. J. Remote Sens., 21, 1183-1199.

Chen, F., Z. Janic, and K. Mitchell, 1997: Impact of atmospheric surface-layer parameterizations in the new land-surface scheme of the NCEP mesoscale Eta model. Bound.-Layer Meteor., 85, 391-421.

Cosby, B. J., G. M. Hornberger, R. B. Clapp, and T. R. Ginn, 1984: A statistical exploration of the relationships of soil moisture characteristics to the physical properties of soils. Water Resour. Res., 20, 682-690.

de Rosnay, P., and J. Polcher, 1998: Modeling root water uptake in a complex land surface scheme coupled to a GCM. Hydrol. Earth. Syst. Sci., 2, 239-356.

Desborough, C. E., 1997: The impact of root weighting on the response of transpiration to moisture stress in a land surface scheme. Mon. Wea. Rev., 125, 1920-1930.

_, 1999: Surface energy balance complexity in GCM land surface models. Climate Dyn., 15, 389-403.

_ A. J. Pitman, and P. Irannejad, 1996: Analysis of the relationship between bare soil evaporation and soil moisture simulated by 13 land surface schemes for a simple non-vegetated site. Global Planet. Change, 13, 47-56.

Dirmeyer, P. A., A. J. Dolman, and N. Sato, 1999: The Global Soil Wetness Project: A pilot project for global land surface modeling and validation. Bull. Amer. Meteor. Soc., 80, 851-878.

Dolman, A. J., and D. Gregory, 1992: The parameterization of rainfall interception in GCMs. Quart. J. Roy. Meteor. Soc., 118, 455467.

_- and E. M. Blyth, 1997: Patch scale aggregation of heterogeneous land surface cover for mesoscale meteorological models. J. Hydrol., 190, 252-268.

__ , and R. Dickinson, 1997: Land surface parameterizations/soil vegetation-atmosphere transfer schemes workshop-Conclusions and working group reports. GEWEX Tech. Rep., IGPO Series Pub. No. 31, La Jolla, CA, 77 pp.

Dümenil, L., and E. Todoni, 1992: A rainfall-runoff scheme for use in the Hamburg climate model. Adv. Theor. Hydrol., 9, 129157.

Durand, Y., E. Brun, L. Mérindol, G. Guyomarc'h, B. Lesaffre, and E. Martin, 1993: A meteorological estimation of relevant parameters for snow schemes used with atmospheric models. Ann. Glaciol., 18, 65-71.

Entekhabi, D., and P. Eagleson, 1989: Land surface hydrology parameterization for atmospheric general circulation models including subgrid scale spatial variability. J. Climate, 2, 816-832.

Entin, J. K., A. Robock, K. Y. Vinnikov, V. Zabelin, S. Liu, A. Namkhai, and T. Adyasuren, 1999: Evaluation of Global Soil Wetness Project soil moisture simulations. J. Meteor. Soc. Japan, 77, 183-198.

Etchevers, P., 2000: Modèlisation du cycle continental de l'eau à l'échelle régional: Impact de la modélization de l'enneigement sur l'hydrologie du bassin versant du Rhône. (Modeling the continental water cycle at a regional scale: Impact of the snow simulation on the hydrology of the Rhone basin). Ph.D. thesis, Université Paul Sabatier, 361 pp.

—_ C. Golaz, and F. Habets, 2001: Simulation of the water budget and the river flows of the Rhône basin from 1981 to 1994. J. Hydrol., 244, 60-85.

Flamiglietti, J. S., and E. F. Wood, 1994: Multiscale modeling of spatially variable water and energy balance processes. Water Resour. Res., 30, 3061-3078.

Ghan, S. J., J. C. Liljegren, W. J. Shaw, J. H. Hubbe, and J. C. Doran, 1997: Influence of subgrid variability on surface hydrology. $J$. Climate, 10, 3157-3166.

Giordano, A., Ed., 1992: CORINE soil erosion risk and important land resources of the European community. EUR Tech. Rep. $13233 \mathrm{EN}, 97 \mathrm{pp}$.

Golaz-Cavazzi, C., P. Etchevers, F. Habets, E. Ledoux and J. Noilhan, 2001: Comparison of two hydrological simulations of the Rhone basin. Phys. Chem. Earth, 26B, 461-466.

Gusev, Ye. M., and O. N. Nasonova, 1998: The land surface parameterization scheme SWAP: Description and partial validation. Global Planet. Change, 19, 63-86.

Habets, F., R. Etchevers, C. Golaz, E. Leblois, E. Ledoux, E. Martin, J. Noilhan, and C. Ottlé, 1999: Simulation of the water budget and the river flows of the Rhone basin. J. Geophys. Res., 104, 31 145-31 172.

Henderson-Sellers, A., and A. Pitman, 1992: Land-surface schemes 
for future climate models: Specification, aggregation, and heterogeneity. J. Geophys. Res., 97, 2687-2696.

— Z Z.-L. Yang, and R. E. Dickinson, 1993: The project for intercomparison of land surface parameterization schemes. Bull. Amer. Meteor. Soc., 74, 1335-1349.

— - A. Pitman, P. Love, P. Irannejad, and T. Chen, 1995: The project for intercomparison of land surface parameterization schemes (PILPS): Phases 2 and 3. Bull. Amer. Meteor. Soc., 76, 489504.

King, D., C. Lebas, M. Jamagne, R. Hardy, and J. Draoussin. 1995: Base de données géographiques des sols de France à l'échelle 1/1000000 (Geographical Soil Database for France at a scale of 1/1000000). Institut National de Recherches Agronomiques (INRA) Tech. Rep., Orleans, France, 100 pp.

Koster, R. D., and M. J. Suarez, 1992: Modeling of the land surface boundary in climate models as a composite of independent vegetation stands. J. Geophys. Res., 97, 2697-2715.

— , and P. C. D. Milly, 1997: The interplay between transpiration and runoff formulations in land surface schemes used with atmospheric models. J. Climate, 10, 1578-1591.

— M. J. Suarez, A. Ducharne, M. Stieglitz, and P. Kumar, 2000: a catchment-based approach to modeling land surface processes in a general circulation model: 1. Model structure. J. Geophys. Res., 105, 24 809-24 822.

Ledoux, E., G. Girard, G. de Marsilly, and J. Deschenes, 1989: Spatially distributed modeling: Conceptual approach, coupling surface water and ground water. Unsaturated Flow Hydrologic Modeling-theory and Practice, X. Morel-Seytoux, Ed., NATO, ASI Series C, Kluwer Academic, 435-454.

Liang, X., and Z. Xie, 2001: A new surface runoff parameterization with subgrid-scale soil heterogeneity for land surface models. Adv. Water. Resour., 24, 1173-1193.

—, D. Lettenmaier, E. F. Wood, and S. J. Burges, 1994: A simple hydrologically based model of land surface water and energy fluxes for general circulation models. J. Geophys. Res., 99, 14 41514428.

_ tistical dynamic representation of subgrid spatial variability of precipitation in the two-layer variable infiltration capacity model. J. Geophys. Res., 101, 21 403-21 422.

Mahfouf, J.-F., and J. Noilhan, 1996: Inclusion of gravitational drainage in a land surface scheme based on the force-restore method. J. Appl. Meteor., 35, 987-992.

—_, and Coauthors, 1996: Analysis of transpiration results from the RICE and PILPS workshop. Global Planet. Change, 13, 73-88.

Meeson, B. W., and Coauthors, 1995: ISLSCP Initiative I-Global Data Sets for Land-Atmosphere Models, 1987-1988, Vols. 1-5. NASA CD-ROM.

Nash, J. E., and J. V. Sutcliffe, 1970: River flow forecasting through conceptual models, 1, A discussion of principles. J. Hydrol., 10, 282-290.

Nijssen, B., and Coauthors, 2002: Simulation of high latitude hydrological processes in the Torne-Kalix basin: PILPS Phase 2(e). 2: Comparison of model results with observations. Global Planet. Change, 38, 31-53.

Noilhan, J., and P. Lacarrère, 1995: GCM gridscale evaporation from mesoscale modeling. J. Climate, 8, 206-223.

—_, and J.-F. Mahfouf, 1996: The ISBA land surface parameterization scheme. Global Planet. Change, 13, 145-159.

Nykanen, D. K., E. Foufoula-Georgiou, and W. M. Lapenta. 2001: Impact of small-scale rainfall variability on larger-scale spatial organization of land-atmosphere fluxes. J. Hydrometeor., 2, $105-121$.
Polcher, J., 2001: GLASS implementation underway. GEWEX News, 10, 9 .

- , and Coauthors, 2000: GLASS: Global Land-Atmosphere System Study. GEWEX News, 10, 3-5.

Sellers, P. J., F. G. Hall, G. Asrar, D. E. Strebel, and R. E. Murphy, 1988: The first ISLSCP Field Experiment (FIFE). Bull. Amer. Meteor. Soc., 69, 22-27.

— Global Data Sets. Vols. 1-5, NASA CD-ROM.

— and Coauthors, 1997: BOREAS in 1997: Experiment overview, scientific results, and future directions. J. Geophys. Res., 102, $28731-28769$.

Seth, A., F. Giorgi, and R. E. Dickinson, 1994: Simulating fluxes from heterogeneous land surfaces: Explicit subgrid method employing the biosphere-atmosphere transfer scheme (BATS). $J$. Geophys. Res., 99, 651-677.

Shmakin, A. B., 1998: The updated version of SPONSOR land surface scheme. PILPS-influenced improvements. Global Planet. Change, 19, 49-62.

Slater, A. G., and Coauthors, 2001: The representation of snow in land surface schemes: Results from PILPS 2(d). J. Hydrometeor., 2, 7-25.

Tanaka, K., E. Nakakita, and S. Ikebuchi, 1998: Land-surface parameterization in the Lake Biwa Project. Annu. J. Hydraul. Eng., 42, 79-84.

van den Hurk, B., and P. Viterbo, 2002: The Torne-Kalix PILPS-2e experiment as a test bed for modifications to the ECMWF land surface scheme. Global Planet. Change, 38, 165-173.

—, P. Viterbo, A. C. M. Beljaars and A. K. Betts, 2000: Offline validation of the ERA40 surface scheme. ECMWF Tech. Memo 295, 43 pp.

Van Genuchten, M. T., 1980: A closed form equation for predicting the hydraulic conductivity of unsaturated soils. Soil Sci. Soc. Amer., 44, 892-898.

Verseghy, D., 2000: The Canadian Land Surface Scheme (CLASS): Its history and future. Atmos.-Ocean, 38, 1-3.

Violette, S., E. Ledoux, P. Goblet, and J. P. Carbonnel, 1997: Hydrologic and thermal modeling of an active volcano: The Piton de la Fournaise, Reunion. J. Hydrol., 191, 37-63.

Wang, G., and E. A. B. Eltahir, 2000: Modeling the biosphere-atmosphere system. The impact of the subgrid variability in rainfall interception. J. Climate, 13, 2887-2899.

Wetzel, P. J., and J. T. Chang, 1988: Evapotranspiration from nonuniform surfaces: A first approach for short-term numerical weather prediction. Mon. Wea. Rev., 116, 600-621.

__ and Coauthors, 1996: Modeling vadose zone liquid water fluxes: Infiltration, runoff, drainage, interflow. Global Planet. Change, 13, 57-71.

Wood, E. F., D. Lettenmaier, and V. Zartarian, 1992: A land-surface hydrology parameterization with subgrid variability for general circulation models. J. Geophys. Res., 97, 2717-2728.

_, and Coauthors, 1998: The Project for Intercomparison of LandSurface Parameterization Schemes (PILPS) Phase-2c Red-Arkansas River Basin experiment: 3. Experiment description and summary intercomparisons. Global Planet. Change, 19, 115135.

Xue, Y., P. J. Sellers, J. L. Kinter, and J. Shukla, 1991: A simplified biosphere model for global climate studies. J. Climate, 4, 345364.

Yang, Z.-L., and G.-Y. Niu, 2002: The versatile integrator of surface and atmospheric processes (VISA) Part 1: Model description. Global Planet. Change, 38, 175-189.

Zhang, H., A. Henderson-Sellers, A. J. Pitman, J. L. McGregor, C. E. Desborough, and J. J. Katzfey, 2001: Limited-area model sensitivity to the complexity of representation of the land surface energy balance. J. Climate, 14, 3965-3986. 